\title{
The Economic Benefits of Midseason Reordering in Apparel Retailing
}

\author{
A. Lamont \\ H. Elayat
}

September 27, 1995

This is an informal report intended primarily for internal or limited external distribution. The opinions and conclusions stated are those of the author and may or may not be those of the Laboratory.

Work performed under the auspices of the U.S. Department of Energy by the Lawrence Livermore National Laboratory under Contract W-7405-Eng-48. 


\section{DISCLAIMER}

This document was prepared as an account of work sponsored by an agency of the United States Government. Neither the United States Government nor the University of California nor any of their employees, makes any warranty, express or implied, or assumes any legal liability or responsibility for the accuracy, completeness, or usefulness of any information, apparatus, product, or process disclosed, or represents that its use would not infringe privately owned rights. Reference herein to any specific commercial product, process, or service by trade name, trademark, manufacturer, or otherwise, does not necessarily constitute or imply its endorsement, recommendation, or favoring by the United States Government or the University of California. The views and opinions of authors expressed herein do not necessarily state or reflect those of the United States Government or the University of California, and shall not be used for advertising or product endorsement purposes.

This report has been reproduced directly from the best available copy.

Available to DOE and DOE contractors from the Office of Scientific and Technical Information P.O. Box 62, Oak Ridge, TN 37831

Prices available from (615) 576-8401, FTS 626-8401

Available to the public from the National Technical Information Service

U.S. Department of Commerce 5285 Port Royal Rd. Springfield, VA 22161 
Demand Activated Manufacturing Architecture Project

\title{
The Economic Benefits of Midseason Reordering in Apparel Retailing
}

\author{
Alan Lamont \\ and \\ Hatem Elayat \\ September 27, 1995 \\ Lawrence Livermore National Laboratory
}




\section{Summary \\ The Economic Benefits of Midseason Reordering}

This study examines the economic benefits of midseason reordering to a retailer in the apparel business. This is important when deciding between an on-shore or an off-shore supplier. Typically, an on-shore supplier will allow reorders part way through a selling season, but an off-shore supplier often does not. The flexibility provided by reordering should increase the net profits of the retailer. Consequently, a method to evaluate the potential benefits of the midseason reordering will help in selecting suppliers.

More broadly, this analysis examines the economic benefits of improved supplier flexibility and responsiveness. The ability to reorder allows the retailer to better match his stocks to the demand over the season, reducing the chances stock out or a mark-down. This study evaluates the benefits that accrue by better matching stock to demands. This framework can be extended to assist the textile industry in evaluating new strategies intended to strengthen the industry based on improving supplier responsiveness.

This report presents a method for determining the value of reordering, explores factors that affect its value, and provides an estimate of the value under a range of conditions.

\section{Scenario analyzed}

The study analyzes a hypothetical case of a retailer selling flannel shirts. It is expected that the retailer will sell 50,000 dozen shirts during the season. The first cost of the shirts is $\$ 6$ per shirt and their retail price is $\$ 12$. The analysis also includes costs of transportation, storage and handling. Two cases of end of season markdown are evaluated, $100 \%$ and $50 \%$. 


\section{Approach}

The analysis models the demand as a simple stochastic process which divides the selling season into a series of two-week periods. Demands in each period are random. The demand in one period is correlated with the demand in the previous period. As both the standard deviation of the period demands and the correlation increase, the uncertainty about the total demand for the season increases. The standard deviation of the period demands and the correlations are varied over a plausible range in the analysis to determine the magnitude of their effects on the benefits of reordering.

The model finds the optimal order quantities for the retailer using a dynamic programming optimization procedure. The value of reordering is determined by first computing the expected profit assuming that reordering is not allowed, and then computing the expected profits assuming that reordering is allowed. The increase in the expected profits when reordering is allowed is the expected benefit of reordering.

\section{Results Of The Analysis}

The results show that the value of reordering depends on uncertainty about future demands and the end of season markdown. As the uncertainty increases, the value of reordering increases. The value of reordering also increases as the size of the markdown increases.

The expected benefit of reordering depends on the assumptions about the markdown price of unsold merchandise at the end of the season. If merchandise cannot be sold at the end of the season (i.e. a $100 \%$ markdown), the "downside risk" to the retailer is large: there is a chance that substantial investments will be made in inventory that cannot be sold. However, if the merchandise can be sold at a markdown of $50 \%$, the downside risk is greatly reduced. If demand turns out to be smaller than expected, there is not much loss. This reduction in risk reduces the expected losses when reordering is not allowed and thus decreases the difference between the expected profits under the two cases. The expected value of re-ordering is substantially smaller when it is assumed that there will be only a $50 \%$ markdown, compared to a $100 \%$ markdown. 
Along with changing value of reordering, the assumed markdown also changes the optimal order quantities. If the markdown is only $50 \%$, there is very little penalty to having left over merchandise at the end of the season. However, there is a large benefit to having extra stock on hand in case demand is high. Consequently, with or without reordering, the optimal amounts to purchase are larger when the markdown is only $50 \%$ as compared to the case of $100 \%$ markdown.

The analysis shows that if there is little uncertainty about the demand, the benefit of reordering is very small. For the case with the largest uncertainty analyzed, we find that at a markdown of $100 \%$, reordering increases the expected season profit for this scenario from $\$ 2.15 \mathrm{M}$ to about $\$ 2.56 \mathrm{M}$, an increase of $19 \%$. For the same uncertainty case with a markdown of $50 \%$, reordering only increased expected profits by $4.5 \%$. Thus both the degree of uncertainty and the end of season markdown have a substantial effect on the value of reordering.

These benefits can be translated into the additional price that a retailer would be willing to pay to a supplier that allows reordering. For the case of maximum uncertainty and $100 \%$ markdown, a retailer would be willing to pay a premium up to $\$ 0.41$ per shirt. If the premium were any higher, the expected profits would be less than the profits expected by buying from a supplier that did not allow reordering. For the same case of uncertainty, but with a markdown of only $50 \%$, a retailer would only be willing to pay premium of $\$ 0.12$ per shirt.

Table S-1 summarizes the results for the case of maximum uncertainty analyzed in the study:

Table S-1: Summary of value of reorder at the maximum level of uncertainty analyzed

\begin{tabular}{|lcc|}
\hline & $\begin{array}{l}\mathbf{5 0} \% \\
\text { markdown }\end{array}$ & $\begin{array}{l}\mathbf{1 0 0 \%} \\
\text { markdown }\end{array}$ \\
\hline Profits with out reorder $(\$ M)$ & 2.789 & 2.149 \\
Profits with reorder $(\$ M)$ & 2.914 & 2.562 \\
Increase in profit $(\$ M)$ & 0.125 & 0.414 \\
$\begin{array}{l}\text { Equivalent premium buyer would pay } \\
\text { for reordering (\$/shirt) }\end{array}$ & 0.12 & 0.41 \\
\hline
\end{tabular}




\section{Possible extensions to the analysis}

The basic analytic approach can be extended to evaluate multiple reorders and various lead times. This will give a clearer understanding of the relationship between supplied responsiveness and retailer profits. This will be valuable in assessing strategies for strengthening the textile industry that are based on improved supplier response. 


\section{Table of Contents}

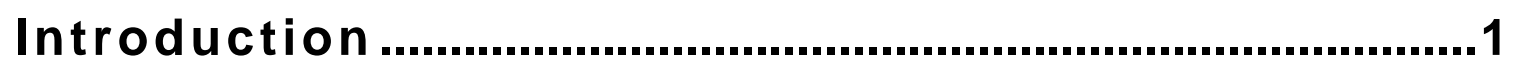

Source of the economic benefits ...............................................................

Relevance of the reordering analysis to

evaluating Quick Response ..........................................................................

Scenario analyzed...................................................................

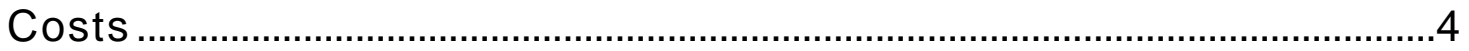

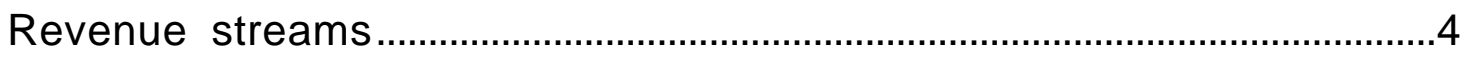

Analytic method ............................................................. 5

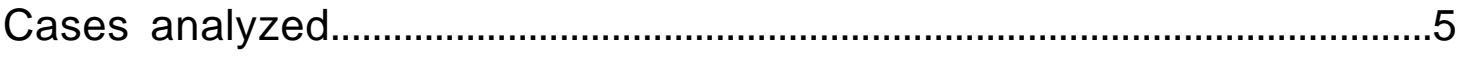

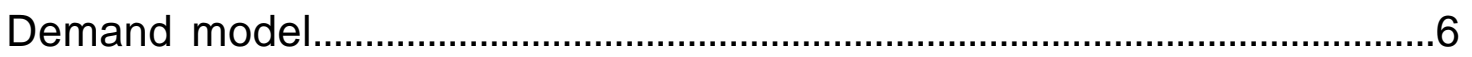

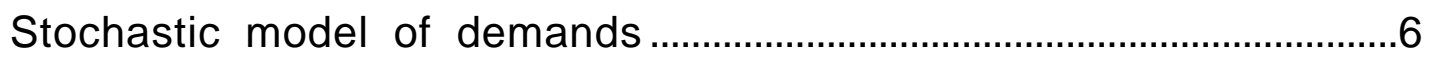

Uncertainty about future demands as a function of

the variance of the disturbance term and the correlation................

Retailer's knowledge of the parameters of the demand model.......9

Summary of demand model.................................................................... 10

Equations and algorithm for computing expected

profits for fixed orders and re-orders ................................................10

Basic method for Cases 1 and 1a- Fixed Order Case........................10

Basic method for Case 2- Reorder Case ............................................12

\section{Results Of The Analysis ...................................................13}

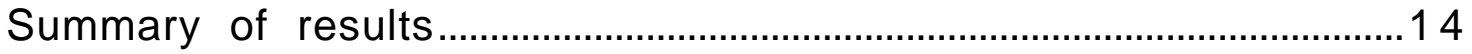

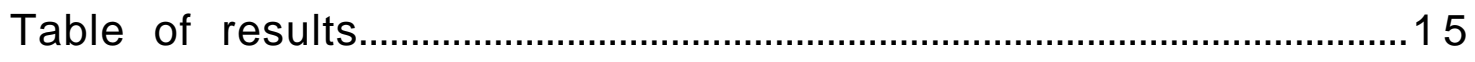

The expected value of profits depends on

statistics of demand and the markdown ..............................................17

The value of reordering depends on the statistical characteristics of the demand 
Value of reordering depends on markdown at the end of the season

Quantities ordered depend on demand statistics and markdown ....21

Impact of reordering on price a retailer is willing to pay................25

Conclusions and indications for further

investigation ....................................................................... 26

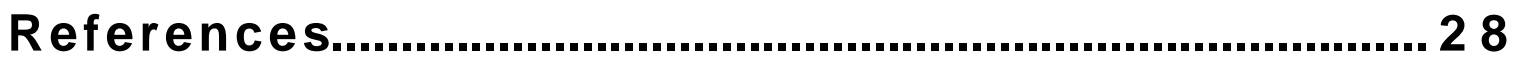

\section{Appendix A Stochastic Demand Model ...........................29}

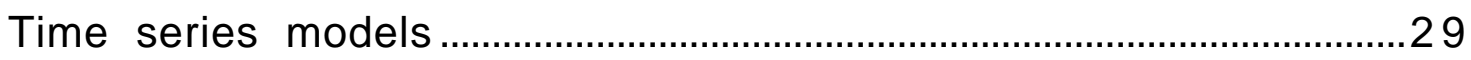

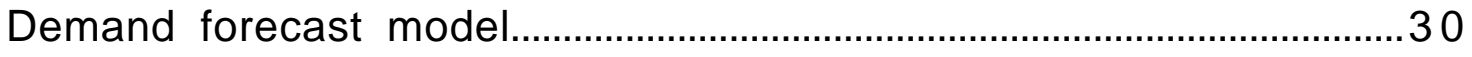

Mean and variance of total demand over several periods...............3 31

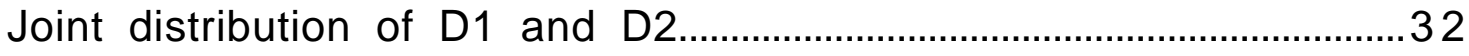

Appendix B Equations for Computing Optimal Order Quantities and Expected Net Present Value For Ordering Decisions............................................................... 33

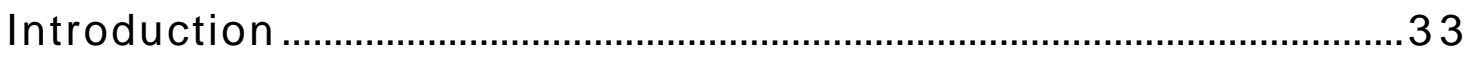

Some Basic Definitions................................................................................... 33

Case Where Orders Are Fixed Before

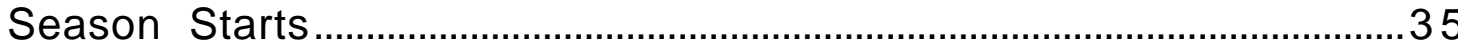

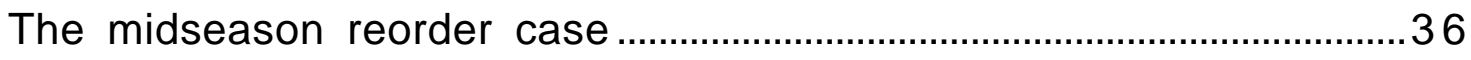




\section{The Economic Benefits of Midseason Reordering}

\section{Introduction}

This study examines the economic benefits of midseason reordering to a retailer in the apparel business. The results are important when deciding between an on-shore or an off-shore supplier. Typically, an on-shore supplier will allow reorders part way through a selling season, but an off-shore supplier often does not. The flexibility provided by reordering should increase the net profits of the retailer. Consequently, a method to evaluate the potential benefits of the midseason reordering will help in selecting suppliers.

More broadly, this analysis examines the economic benefits of improved supplier flexibility and responsiveness. The framework can be extended to assist the textile industry in evaluating new strategies intended to strengthen the industry based on improving supplier responsiveness.

This report presents a method for determining the value of reordering, explores factors that affect its value, and provides an estimate of the value under a range of conditions. The method is based on a stochastic process model of the demands the retailer faces. It uses a dynamic programming model to determine the optimal quantities to order and the expected profits. The analysis shows that the benefits of reordering are quite sensitive to the uncertainties in the demand and to the assumptions about the markdown of unsold merchandise at the end of the season. 


\section{Source of the economic benefits}

The ability to reorder provides value to the retailer in two ways: First, it increases the likelihood that the retailer's stocks will match the customer demand. This reduces the chance of a stock out during the season (and the lost sales) and decreases the chance of mark-downs at the end of the season. Second, reordering allows the retailer to spread out purchases over the season. This reduces the carrying costs of stock. Because the effect of reordering on the carrying costs can be readily calculated from discounted cash flow analysis, this study focuses on the benefits that accrue by better matching stock to demands.

The value gained from better matching stock to demand depends on the degree of uncertainty in demand that the retailer faces. If total demand during a season were known exactly, there would be no value to reordering (other than reducing carrying costs). The retailer would order exactly the right amount. There would be no losses due to stockouts or markdowns.

However, when demand is uncertain, there is always a chance of stockouts or markdowns. Midseason reordering allows a retailer to make use of information about past sales to make a better decision about how much to buy for the next periods. The value of reordering is greatly increased if the past information can give the retailer a better forecast ${ }^{1}$ of the demand in coming periods. If it does provide information, and if the retailer has a sound decision procedure to use the information to make better orders, then the value of reordering increases.

In this study the economic value of reordering is computed by comparing the expected profits obtained when orders must be fixed at the start of the season to the expected profits when reordering is allowed at midseason. The difference between these is the value of the reordering. We examine its values as a function of the statistical characteristics of the demand the retailer faces and the anticipated markdown of unsold merchandise at the end of the season. The impacts of the demand statistics and the markdown on the retailer's ordering policies are also discussed.

\footnotetext{
$1 \quad$ Here a "better" forecast means that the variance of the difference between the forecast quantity and the actual quantity is smaller.
} 


\section{Relevance of the reordering analysis to evaluating Quick Response}

The option to reorder is a simple form of Quick Response. This analysis demonstrates a basic framework for exploring the value of Quick Response. Here we only compare the case of (essentially) no response and the case where one reorder is allowed during the season with immediate delivery (zero lead time). This analysis could be extended to evaluate the case of several orders during the season with different lead times. It would be of particular interest to determine if a) the value of the quick response increases significantly as more reorders are allowed and lead time is reduced, or b) simply allowing one reorder (as is analyzed here), captures most of the value that is available.

\section{Scenario analyzed}

The study analyzes a hypothetical case of a retailer selling flannel shirts. These shirts are sold during a three month season, July through September. It is expected that the retailer will sell 50,000 dozen shirts during the season. However, there is uncertainty about the actual amount, as is described later.

Under this scenario the retailer places an order for a portion of the shirts 16 weeks before the sales season starts. Half way through the season, the retailer has the option of ordering additional shirts. It is assumed that the supplier has continued to produce shirts and has enough stock on hand to deliver the reordered shirts on a few days notice.

The timeline for events in the scenario is as follows:

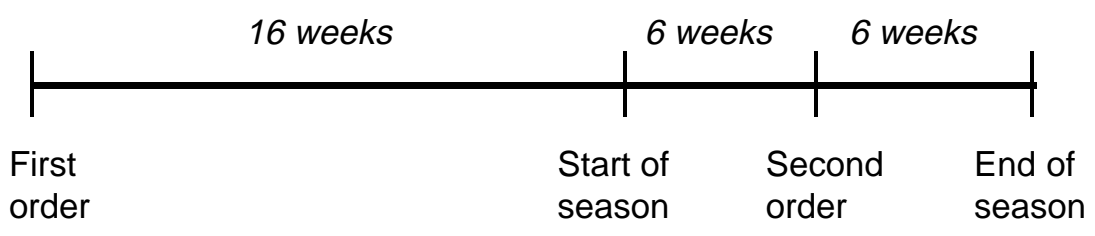




\section{Costs}

Several costs must be taken into account in addition to the first cost of the shirts. The costs are shown in Table 1:

Table 1: $\quad$ Costs associated with purchasing a single shirt

\begin{tabular}{|c|c|}
\hline Cost Component & $\begin{array}{c}\text { Cost per shirt } \\
(\$)\end{array}$ \\
\hline First cost & 6.00 \\
\hline Shipping costs & 0.05 \\
\hline $\begin{array}{l}\text { Storage and handling at } \\
\text { warehouse }\end{array}$ & 0.03 \\
\hline Pick, pack and label & 0.25 \\
\hline Preparation & 0.25 \\
\hline
\end{tabular}

For the first order, it is assumed that the first cost is paid at the time of the order. The shipping, storage, pick pack and label (PPL), and the preparation costs are incurred at the time the items are delivered, which is at the start of the season. Thus all the costs except the first cost are discounted back from the start of the season to the time of first order. For the second order, it is assumed that all of the costs (including first cost) are incurred at the time of the second order, which is half way through the season. Thus all of these costs are discounted back from the middle of the season to the time of the first order. In either case, the supplier pays storage cost until the shirts are delivered to retailer.

The interest rate is assumed to be $12 \%$. Based on these costs and the timing of expenses, we can calculate the present value of all costs per shirt. For the initial order the total discounted cost is $\$ 6.56$. For a shirt ordered part way through the season, the cost is $\$ 6.14$.

\section{Revenue streams}

The selling price per shirt is $\$ 12.00$. The revenues are assumed to accrue uniformly during each half of the season. That is, for each half, the total sales are determined. Then it is assumed that this amount was sold at a uniform rate during the half season. This income stream is then discounted back to the time of the first order. 


\section{Analytic method}

This study computes the expected benefits that can accrue to a retailer if a supplier allows re-ordering midway through the season. To compute this benefit, we compute the expected net discounted revenue (profit) for the case where no reordering is allowed and compare it to the revenues for the case where reordering is allowed. The difference is the expected benefit that arises from the midseason reordering. The specific cases are described below.

\section{Cases analyzed}

Case 1- No Reorder Case: The total quantity of shirts acquired for sale during the season is bought and paid for at the time of initial order (16 weeks before the start of the season). All ancillary costs are incurred when the shirts are delivered. Under this case the retailer determines the optimal amount to order, given that it is all paid for and delivered before the start of the season.

Case 2 - Reorder Case: One batch of shirts is bought and paid for at the initial order time (16 weeks before the start of the season). Under this case the retailer determines the optimal amount to purchase for the first part of the season taking into account his estimates of demand and the fact that he can adjust his midseason order to better fit the demand that materialize. Part way through the season the retailer evaluates the expected demand for the rest of the season and the stock on hand. He decides how many additional shirts are needed and places a reorder. All costs for the reorder are incurred at the time of reorder.

Note that Case 1 and Case 2 are not quite comparable. In Case 1 the first cost of the shirts is paid at the time of first order, while under Case 2 the first costs for some of the shirts are paid for at the time of reorder. Thus Case 2 includes a benefit from delaying the ordering time that is not included in Case 1. Comparing these two cases does not allow us to compute the additional value that is solely due to the flexibility of reordering and to the increased likelihood that we will be able to match stocks to demand. Therefore we formulated Case $1 \mathrm{a}$.

Case 1a - Fixed Order Case: At the start of the season, the retailer commits to the quantities for the first and second halves of the 
season. Thus the orders are fixed at the outset. The orders are paid for in two batches. The first one is paid for at the time of initial order (while the shipping, storage, PPL and preparation costs are paid for when the shirts are delivered). The second batch is paid for, including the ancillary costs, at the time of reorder, half-way through the season. Thus the payment streams for Case 2 and Case 1a are comparable. The difference between the expected profits will reflect the value of the flexibility that reordering allows.

To complete the analysis two things are needed 1) a model of the demand process, and 2) an algorithm for finding the optimal order policies and the expected net revenues for these policies.

\section{Demand model}

Demand during any future period follows a stochastic model. However, it is assumed that it follows a statistical model. Under the model used here, the demands from one period to the next may be correlated. This means that if the demand in one period is higher than average, the demand in the next period will also tend to be higher than average. Since these results are exploratory, we have run several different cases with different degrees of correlation (including 0 correlation). The equation for the model and the use of the model in forecasting are discussed in Appendix A. This section will summarize the model and its implications.

Here the season is assumed to last for three months. The analysis is structured to have six periods of two weeks each. Thus each half of the season consists of three periods of two weeks. At the start of the second half the retailer forecasts the total amount demanded during the remaining three periods (i.e. six weeks).

Stochastic model of demands

The demand model provides a probability distribution over the demand for any future period. When forecasting demand for future periods, one would generally expect that the degree of uncertainty (e.g. the variance of the distribution) will increase the further out in the future that one attempts to forecast. This reflects the fact that the further we try to forecast in the future, the more likely that other events will occur to affect the demand. It is desirable that the model can reflect this divergence of the probability distribution. 
In this case, a simple model of a stochastic process with autocorrelation has been used. The model assumes that at the start of the season, there is some expected demand each period (it could, in principle, be a different expected demand for each future period, but that is not assumed here). If in some future period, the actual demand is higher (lower) than the expected demand, then the demand in the following period is expected to be higher (lower) than the expected demand, although not as much higher or lower. In practical terms, we generally expect the conditions that caused demand to deviate from the expected during one period will tend to persist for future periods. The basic equation for this model is:

$$
\tilde{\mathrm{x}}_{\mathrm{t}+1}=\phi \bullet \tilde{\mathrm{x}}_{\mathrm{t}}+\mathrm{e}_{\mathrm{t}}
$$

where:

$$
\begin{array}{ll}
\tilde{\mathrm{x}} \quad= & \text { the difference between the actual realized value and } \\
& \text { the expected value, or } \\
\tilde{\mathrm{x}}_{\mathrm{t}} \quad= & d_{\mathrm{t}}-\mu \\
\mathrm{d}_{\mathrm{t}} \quad= & \text { the realized demand in period } \mathrm{t} \\
\mu \quad= & \text { the expected demand for one period (assumed here to } \\
\phi \quad & \text { be constant for all periods } \\
\mathrm{e}_{\mathrm{t}} \quad= & \text { the correlation coefficient }
\end{array}
$$

The disturbance terms are assumed to be normally distributed with zero mean and a standard deviation of $\sigma$. The disturbances are uncorelated.

In much of the discussion the standard deviation of the disturbance term is expressed as a fraction of the expected demand in one period. Values of $0.0,0.1,0.2$, and 0.3 are used. Since the expected demand is $8.33 \mathrm{k} \mathrm{doz}$, a value of 0.1 corresponds to a standard deviation of $0.833 \mathrm{k} \mathrm{doz}$.

The disturbance term represents the random variability in the demands. If its standard deviation is large, then the actual demands tend to be widely distributed around the average value. If the standard deviation were 0 , then the realized demands would always 
be exactly equal to the average demand and there would be no uncertainty about future demands.

The value of $\phi$ represents the dependence, or correlation, between demands in successive periods. As an example, if the demand in one period were $1 \mathrm{k}$ doz greater than the average value, then we would expect the demand in the next period to be $(\phi \cdot 1 \mathrm{k}$ doz) greater than the average demand.

Because of this correlation, information about previous demands allows a retailer to make a more accurate forecast of future demands. This model allows us to compute the mean and the variance of the demand in any future period. We can also compute the mean and the variance for the sum of the demands in any sequence of future periods. The algorithm for computing the optimal order amounts makes use of this information.

The standard deviation of the demand in the next period is simply equal to $\sigma_{\varepsilon}$. However, if the correlation is greater than 0 , the standard deviation of demand forecast increases the further in the future one forecasts. As is shown in Appendix A, the variance of the forecast $\tau$ periods in the future is:

$$
\operatorname{Var}(\tau)=\left\{1+\sum_{\mathrm{j}=1}^{\tau-1} \phi^{2 \mathrm{j}}\right\} \sigma^{2}
$$

where:

$$
\begin{aligned}
\operatorname{Var}(\tau)= & \text { the variance of the forecast distribution } \tau \text { periods in } \\
& \text { the future. }
\end{aligned}
$$

Note that the rate at which the variance grows is a function of the correlation, $\phi$. The larger the correlation, the more uncertain we are about the demand in future periods. This arises since a high correlation implies that events that cause a deviation from the mean tend to persist and accumulate over time. Whereas low correlation implies that events causing deviations from the mean do not tend to persist and the demand quickly tends to return to the expected value after the event.

Appendix $A$ also includes the equations for the expected value and variance of the total demand over a series of periods. 
Uncertainty about future demands as a function of the variance of the disturbance term and the correlation

The uncertainty about the demand in each future period and the total demand over the season are functions of the variance of the disturbance term and the correlation between demands.

Here we can illustrate the relationship between the parameters and the total demand. Figure 1 shows the relationship between the standard deviation of total season demand and the standard deviation of the disturbance term and the correlation between demands each period. The equation for the standard deviation of total demand is given in Appendix A.

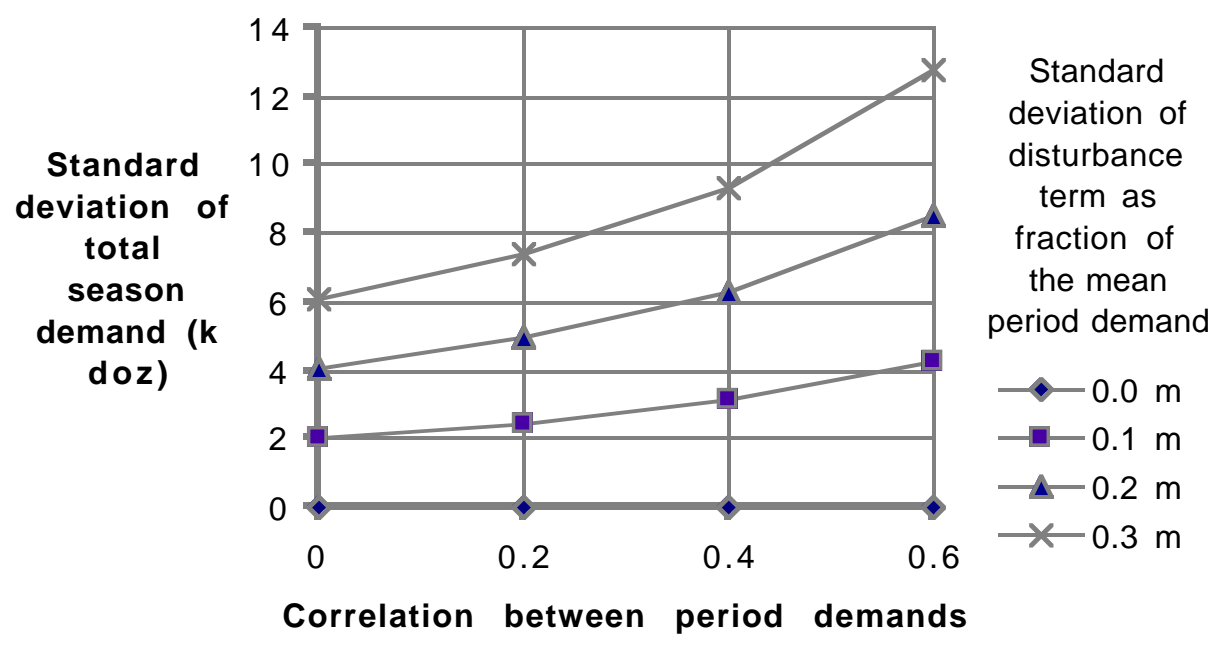

Figure 1: The standard deviation of the total season's demand depends on the standard deviation of the disturbance term and the correlation between demands

We can see here that the uncertainty about total demand increases as the standard deviation of the disturbance term increases and as the correlation increases. Much of the discussion below will focus on the impact of this increasing uncertainty on expected profits and the retailer's optimal purchasing policies.

Retailer's knowledge of the parameters of the demand model

In this analysis it is assumed that the retailer knows the statistics of the demand process, $\mu, \phi$, and $\sigma$, and uses that information to make forecasts and set order quantities. The 
analysis here estimates the value of reordering when the parameters of the demand are well understood.

Since the analysis assumes that the retailer knows the statistics of the demand process the results reflect the benefit of using information and optimal forecasts alone.

If the retailer did not know the parameters of the demand, some additional economic benefits would arise from learning about the underlying demand process. The retailer could observe the demand for a period, update the estimate of the demand parameters, and then make a new order based on this update. If future reorder quantities are based on these improved parameter estimates, the overall net return to the retailer should improve. Nuttle et al provides such a case where the demands from period to period are not correlated, but there are significant benefit to reordering.

We should note that when it is assumed that the underlying parameters of the demand are not known, the value of reordering could be very large. An analysis could, in fact, compute an arbitrarily large benefit by simply assuming that the initial estimate had a very large error.

Summary of demand model

This basic demand model provides a simple representation of a demand process which allows for correlation. If correlation is present, then the retailer can use the information about past demands to make a forecast. We note that the analysis below shows that even in the absence of correlation, past information is still relevant and useful.

\section{Equations and algorithm for computing expected profits for fixed orders and re-orders}

This section gives an overview of the equations and the algorithms used to determine the optimal order policies and the resulting expected profits. Appendix $B$ gives the details of the equations.

Basic method for Cases 1 and 1a-Fixed Order Case

Under Case 1 and 1a, the retailer decides the amounts to purchase for each half of the season before the start of the season. For our analysis it is only necessary to compute the total expected 
revenue given the specified quantities and the probability distribution over demands in both parts of the season. This is done by writing an expression for total discounted revenues as a function of the quantities purchased and the demands in the first and second half of the season. The complete expression is given in Appendix B. For this discussion let this expression to total discounted revenues be

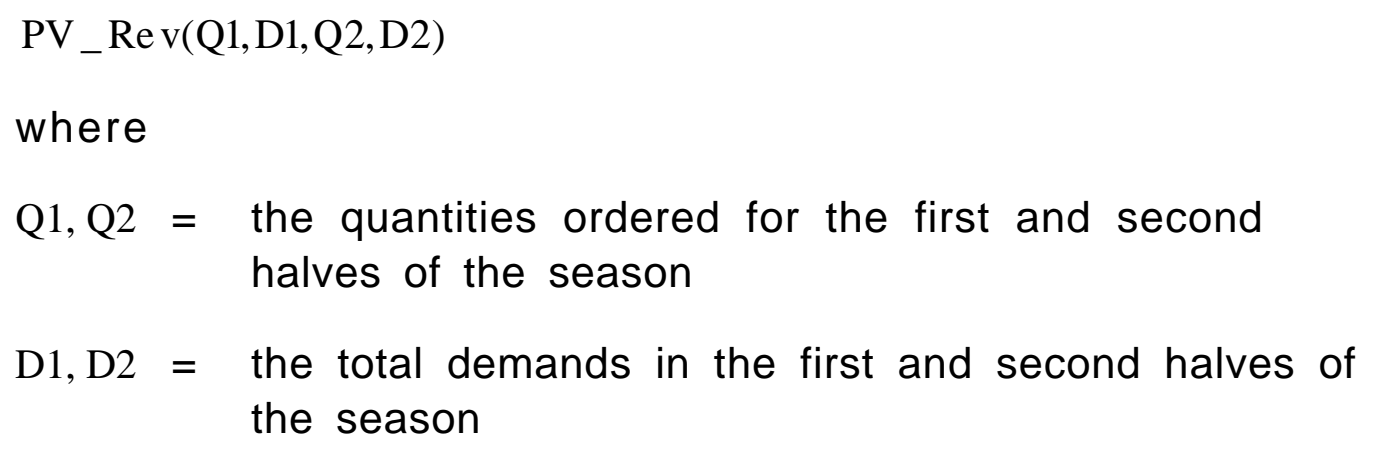

From the demand model, we can derive the expression for the joint probability density function over the demands in the first and second half of the season (D1 and D2) (see Appendix A for the method used to compute the density function). The expected present value of revenues is then just

$$
E P V \_R e v(Q 1, Q 2)=\iint_{D 1} P V_{-} \operatorname{Rev}(Q 1, D 1, Q 2, D 2) \bullet f(D 1, D 2)
$$

where

$f(D 1, D 2)=$ the joint distribution over the demand in the first and second halves of the season.

To complete the calculation, the present value of the costs is directly calculated from the present value of cost for shirts ordered in first and second parts of the season presented earlier.

It is assumed that the retailer will order the optimum quantities to maximize expected net revenue. This analysis simply searches for the optimum by varying the total amount and the amount to be purchased in the first half.

The equations for these expressions are shown in Appendix B. 


\section{Basic method for Case 2- Reorder Case}

In Case 2 the retailer decides how much to order for the first part of the season (using the analysis presented below). After observing the demand for the first half, he decides how much to order for the second half. The amount to order for the second half depends on how much stock is on hand at the end of the first half, and the forecast demand for the second half. Thus, the analysis only determines the optimal amount to be purchased for the first half. The amount purchased for the second half is probabilistic.

The complete equations are described in Appendix B. This section gives an overview of the method. Our goal here is to develop an equation for the expected profits as a function of the quantity ordered in the first half of the season. One can then use the equation to determine the quantity that reduces the largest expected profit. This analysis uses a dynamic programming model and recursive equations. The steps are outlined below.

Basically the equation is developed by working backward from the end of the season to the start. We first derive an expression for the expected profits in the second half, as a function of the amount purchased in the first half and the demand in the first half. This expression is built by first writing the expression for the profits in the second half as a function of

- the amount purchased in the first half, Q1,

- the amount purchased in the second half, Q2,

- the demand in the first half, D1, and

- the demand in the second half, D2.

Given these four values one can determine the stock on hand at the start of the second half and the quantities purchased and sold during the second half. We can also derive an expression for the profits in the second half. This expression is denoted $V_{2}(D 1, Q 1, D 2, Q 2)$. The full expression is given in Appendix B.

The expected value of the second period net revenues is computed by integrating over the distribution over demand in the second half:

$$
\overline{\mathrm{V}}_{2}(\mathrm{D} 1, \mathrm{Q} 1, \mathrm{Q} 2)=\int_{\mathrm{D} 2} \mathrm{~V}_{2}(\mathrm{D} 1, \mathrm{Q} 1, \mathrm{D} 2, \mathrm{Q} 2) \bullet \mathrm{f}(\mathrm{D} 2 \mid \mathrm{D} 1)
$$


(the expression for $f(D 2 \mid D 1)$ is derived in Appendix $A)$.

Finally, the optimal expected value for net revenues in the second half is computed by taking the maximum over Q2:

$$
\overline{\mathrm{V}}_{2}^{*}(\mathrm{D} 1, \mathrm{Q} 1)=\max _{\mathrm{Q} 2}\left[\overline{\mathrm{V}}_{1}(\mathrm{D} 1, \mathrm{Q} 1, \mathrm{Q} 2)\right]
$$

Note that Q2 is a decision that the retailer makes. Here we are assuming that he will make an optimal decision, given his decision in the first half (i.e. Q1) and the demand that actually materialized (D1). Using this equation, we can compute the expected profits in the second half as a simple function of Q1 and D1.

We can write the expression for net discounted revenues in the first half as a function of the quantity purchased and the demand. This is denoted $\mathrm{NR}_{1}(\mathrm{D} 1, \mathrm{Q} 1)$. The total value of the first half net revenues, plus the maximum expected value for the second half net revenues is

$$
\mathrm{V}_{1}(\mathrm{D} 1, \mathrm{Q} 1)=\mathrm{NR}_{1}(\mathrm{D} 1, \mathrm{Q} 1)+\overline{\mathrm{V}}_{2}^{*}(\mathrm{D} 1, \mathrm{Q} 1)
$$

The total expected net revenues over both halves, given $\mathrm{Q} 1$, is found by integrating over D1:

$$
\bar{V}_{1}(\mathrm{Q} 1)=\int_{D 1} \mathrm{~V}_{1}(\mathrm{D} 1, \mathrm{Q} 1) \cdot \mathrm{f}(\mathrm{D} 1)
$$

The expression for $f(D 1)$ is derived in Appendix A.

Finally, the expected value of the optimal decision is found by taking the maximum over Q1:

$$
\overline{\mathrm{V}}_{1}^{*}=\max _{\mathrm{Q} 1}\left[\overline{\mathrm{V}}_{1}(\mathrm{Q} 1)\right]
$$

The optimal quantity to order for the first half is the value of Q1 that maximizes the expression. This allows us to write out an expression for the expected net benefits of the reordering case.

\section{Results Of The Analysis}

The results show that the value of reordering depends on uncertainty about future demands and the end of season markdown. As the uncertainty increases, the value of reordering increase. The 
value of reordering also increases as the size of the markdown increases. This section first gives an overview of these results and the intuition behind them. It then presents several sections that examine specific results in more detail.

\section{Summary of results}

The relationship between total expected profits and the uncertainty is a fundamental feature of the results. The total expected profits decline as the uncertainty in the future demands increase for both the fixed order and the reorder cases. This arises because there is a higher probability (i.e. a greater frequency) of either having too little stock to meet the demand, or having too much. The decline in expected profits happens whether uncertainty increases due to a higher standard deviation in the disturbance term, or a higher correlation from period to period. The difference in expected profits between the cases arises because the expected profits decline more rapidly when orders are fixed ahead of time. As uncertainty increases, there can be a substantial difference between the expected profits with and without reordering.

Next we observe that the expected benefit of reordering depends on the assumptions about the markdown price of unsold merchandise at the end of the season. If merchandise cannot be sold at the end of the season (i.e. a 100\% markdown), the "downside risk" to the retailer is large: there is a chance that substantial investments will be made in inventory that cannot be sold. However, if the merchandise can be sold at a modest markdown (here we assume $50 \%$ ), the downside risk is greatly reduced. In this analysis, the sales price of the garments is $\$ 12$. At a $50 \%$ markdown, it can be sold for $\$ 6$, which is only slightly below its cost. Thus, if demand turns out to be smaller than expected, there is not much loss. This reduction in risk reduces the expected losses of the fixed order case and thus decreases the difference between the expected profits under the two cases. The expected value of re-ordering is substantially smaller when it is assumed that there will be only a $50 \%$ markdown, compared to a $100 \%$ markdown.

Along with changing value of reordering, the assumed markdown also changes the optimal purchasing policies. If the markdown is only $50 \%$, there is very little penalty to having left over merchandise at the end of the season. However, there is a large 
benefit to having extra stock on hand in case demand is high.

Consequently, for both cases, the optimal amounts to purchase are larger when the markdown is only $50 \%$ as compared to the case of $100 \%$ markdown.

The sections below present the numerical results in a table and a discussion the graphically presents the key results.

\section{Table of results}

Table 2 shows the results for all cases analyzed in this study. The definition of the columns are as follows:

SD Disturbance is the standard deviation of the disturbance term as a fraction of the expected value for each period. For example, the value 0.1 indicates that the Standard deviation of the disturbance term is $0.1 \times 8.33 \mathrm{k} \mathrm{doz}$. This is commonly known as the "coefficient of variation".

Correlation is the period to period correlation of the demands.

\section{Fixed order case}

Max Expected value is the expected value of profits when first and second order quantities are set at their optimal values.

Opt. Total Quantity is the optimal total quantity to order for the entire season, when the order quantities are fixed at the start of the season.

Opt. First Order is the optimal quantity to order for the first part of the season when the quantities are fixed at the start of the season.

\section{Reorder Case}

Max. Expected Value is the expected value of profits when the first order quantity is set at its optimal value. Note that the second quantity ordered is probabilistic and is not known until the start of the second half of the season.

Opt. First Order is the optimal quantity to order for the first half of the season for the reorder case.

\section{Value of Reorder}


This is the difference between the Max. Expected Value for the reorder case and the Max. Expected Value for the fixed order case.

Table 2: Results of analysis for all cases

\begin{tabular}{|c|c|c|c|c|c|c|c|}
\hline \multirow{2}{*}{\begin{tabular}{|c|} 
SD \\
distur- \\
bance \\
(fraction \\
of the \\
expected \\
period \\
demand)
\end{tabular}} & \multirow{2}{*}{$\begin{array}{l}\text { Cor- } \\
\text { relation }\end{array}$} & \multicolumn{3}{|c|}{ Fixed Order Case } & \multicolumn{2}{|c|}{ Reorder Case } & \multirow{2}{*}{$\begin{array}{l}\text { Value of } \\
\text { Reorder } \\
\qquad(\$ M)\end{array}$} \\
\hline & & $\begin{array}{c}\text { Max } \\
\text { Expected } \\
\text { Value } \\
(\$ M)\end{array}$ & $\begin{array}{c}\text { Opt. } \\
\text { Total } \\
\text { Quantity } \\
\text { (k doz) }\end{array}$ & $\begin{array}{c}\text { Opt. } \\
\text { First } \\
\text { Order } \\
\text { (k doz) }\end{array}$ & $\begin{array}{c}\text { Max } \\
\text { Expected } \\
\text { Value } \\
(\$ M)\end{array}$ & $\begin{array}{c}\text { Opt. } \\
\text { First } \\
\text { Order } \\
(k \text { doz })\end{array}$ & \\
\hline \multicolumn{8}{|c|}{ Markdown $\quad 100 \%$} \\
\hline $\begin{array}{l}0.1 \\
0.1 \\
0.1 \\
0.1\end{array}$ & $\begin{array}{l}0.0 \\
0.2 \\
0.4 \\
0.6\end{array}$ & $\begin{array}{c}2.862 \\
2.827 \\
2.758 \\
2.586\end{array}$ & $\begin{array}{l}50 \\
50 \\
50 \\
49\end{array}$ & $\begin{array}{l}26.0 \\
26.5 \\
27.0 \\
26.0\end{array}$ & $\begin{array}{l}2.896 \\
2.876 \\
2.842 \\
2.759\end{array}$ & $\begin{array}{l}26.5 \\
28.0 \\
28.0 \\
28.0\end{array}$ & $\begin{array}{l}0.034 \\
0.049 \\
0.084 \\
0.173\end{array}$ \\
\hline $\begin{array}{l}0.2 \\
0.2 \\
0.2 \\
0.2\end{array}$ & $\begin{array}{l}0.0 \\
0.2 \\
0.4 \\
0.6\end{array}$ & $\begin{array}{l}2.746 \\
2.679 \\
2.562 \\
2.336\end{array}$ & $\begin{array}{l}50 \\
50 \\
49 \\
48\end{array}$ & $\begin{array}{l}27.5 \\
27.5 \\
27.5 \\
27.5\end{array}$ & $\begin{array}{l}2.812 \\
2.781 \\
2.738 \\
2.650\end{array}$ & $\begin{array}{l}29.5 \\
29.5 \\
31.0 \\
31.0\end{array}$ & $\begin{array}{l}0.066 \\
0.102 \\
0.176 \\
0.314\end{array}$ \\
\hline $\begin{array}{l}0.3 \\
0.3 \\
0.3 \\
0.3\end{array}$ & $\begin{array}{l}0.0 \\
0.2 \\
0.4 \\
0.6\end{array}$ & $\begin{array}{l}2.628 \\
2.544 \\
2.403 \\
2.149 \\
\end{array}$ & $\begin{array}{l}50 \\
50 \\
49 \\
48\end{array}$ & $\begin{array}{l}27.0 \\
29.0 \\
29.0 \\
26.5\end{array}$ & $\begin{array}{l}2.728 \\
2.689 \\
2.644 \\
2.562 \\
\end{array}$ & $\begin{array}{l}30.5 \\
32.0 \\
33.5 \\
34.5\end{array}$ & $\begin{array}{l}0.100 \\
0.145 \\
0.241 \\
0.413 \\
\end{array}$ \\
\hline \multicolumn{8}{|c|}{$\begin{array}{ll}\text { Markdown } \quad 50 \% \\
\end{array}$} \\
\hline $\begin{array}{l}0.1 \\
0.1 \\
0.1 \\
0.1\end{array}$ & $\begin{array}{l}0.0 \\
0.2 \\
0.4 \\
0.6\end{array}$ & $\begin{array}{l}2.943 \\
2.935 \\
2.914 \\
2.853\end{array}$ & $\begin{array}{l}52 \\
53 \\
54 \\
58\end{array}$ & $\begin{array}{l}27.0 \\
27.0 \\
27.0 \\
28.5\end{array}$ & $\begin{array}{l}2.946 \\
2.942 \\
2.931 \\
2.898\end{array}$ & $\begin{array}{l}28.0 \\
28.0 \\
27.5 \\
28.0\end{array}$ & $\begin{array}{l}0.003 \\
0.007 \\
0.017 \\
0.045\end{array}$ \\
\hline $\begin{array}{l}0.2 \\
0.2 \\
0.2 \\
0.2\end{array}$ & $\begin{array}{l}0.0 \\
0.2 \\
0.4 \\
0.6\end{array}$ & $\begin{array}{l}2.907 \\
2.892 \\
2.867 \\
2.810\end{array}$ & $\begin{array}{l}55 \\
56 \\
60 \\
66\end{array}$ & $\begin{array}{l}29.0 \\
29.0 \\
31.0 \\
31.0\end{array}$ & $\begin{array}{l}2.923 \\
2.915 \\
2.905 \\
2.895\end{array}$ & $\begin{array}{l}29.0 \\
29.5 \\
31.0 \\
32.5\end{array}$ & $\begin{array}{l}0.016 \\
0.023 \\
0.038 \\
0.085\end{array}$ \\
\hline $\begin{array}{l}0.3 \\
0.3 \\
0.3 \\
0.3\end{array}$ & $\begin{array}{l}0.0 \\
0.2 \\
0.4 \\
0.6\end{array}$ & $\begin{array}{l}2.872 \\
2.857 \\
2.839 \\
2.789\end{array}$ & $\begin{array}{l}58 \\
60 \\
64 \\
72\end{array}$ & $\begin{array}{l}30.5 \\
32.0 \\
34.0 \\
33.5\end{array}$ & $\begin{array}{l}2.893 \\
2.885 \\
2.894 \\
2.914\end{array}$ & $\begin{array}{l}31.5 \\
32.0 \\
33.5 \\
35.0\end{array}$ & $\begin{array}{l}0.021 \\
0.028 \\
0.055 \\
0.125\end{array}$ \\
\hline
\end{tabular}

The following sections show some of the highlights of these results 


\section{The expected value of profits depends on statistics of demand and the markdown}

The demand is parameterized by the standard deviation of the disturbance term-described as a fraction of the expected demand each period-and the correlation between demands each period. As either of these parameters increase, the total uncertainty in the season demand increases. As the total uncertainty increases, the expected profits decline since the chances of either a stockout or excess stocks increase.

Figure 2 shows the expected profits as a function of the statistics of the demand for the fixed order case. The expected profits drop quickly as the uncertainty increases.

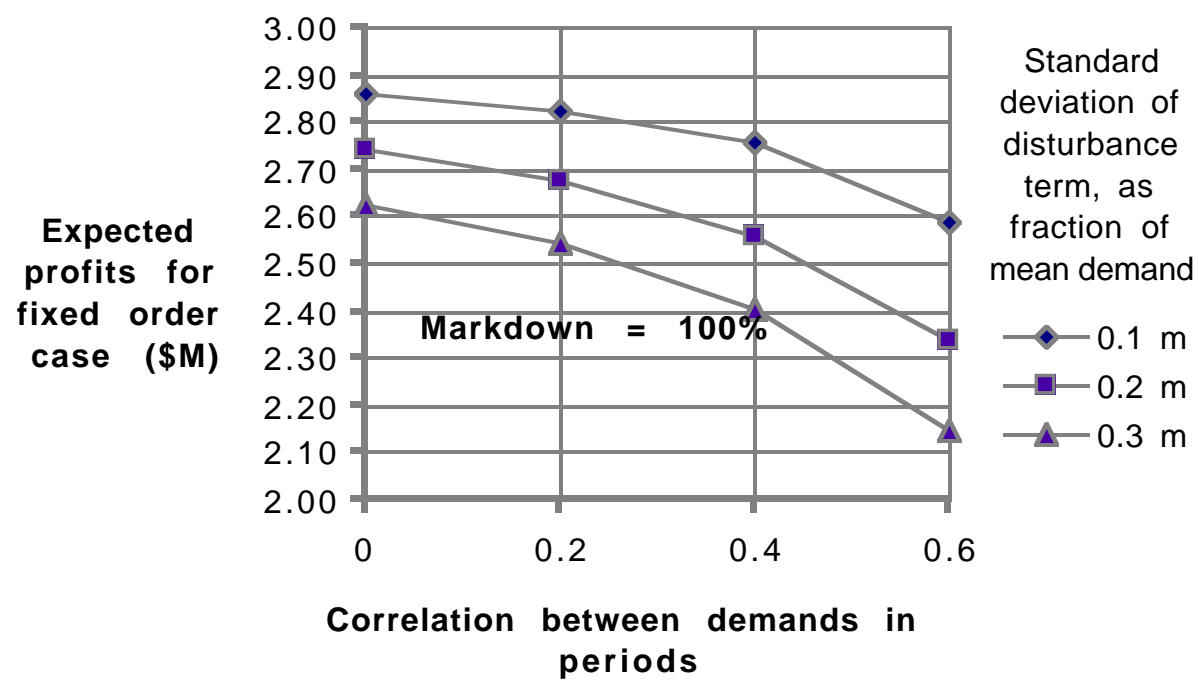

Figure 2: Expected profits decline as the uncertainty increases when orders are fixed at the start of the season

Figure 3 shows the expected profits for the reorder case. Expected profits do not decline as quickly when uncertainty increases since the reordering allows the retailer the chance to change orders part way through the season and thus avoid excess stocks, or take advantage of an unexpectedly large demand. 


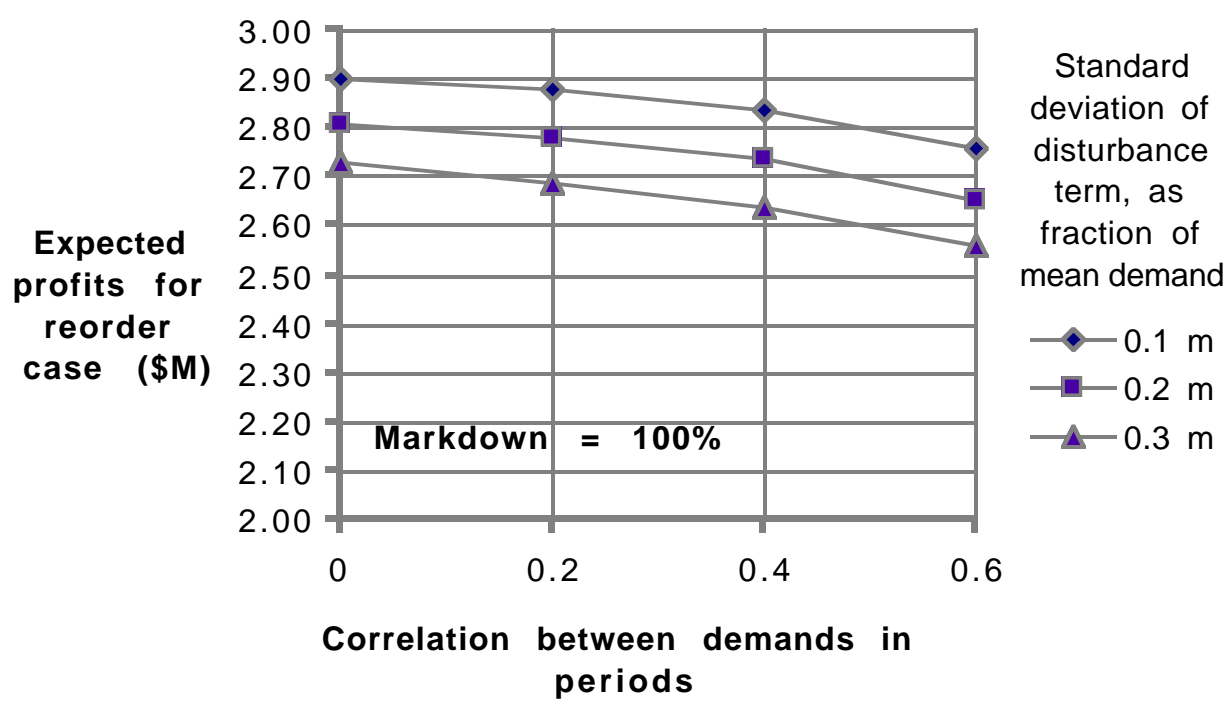

Figure 3: The decline in expected profits with uncertainty is smaller when reorders are allowed

\section{The value of reordering depends on the statistical characteristics of the demand}

For this analysis the value of reordering is calculated as the difference between the expected profits when reordering is allowed and the expected profits when fixed orders must be made at the start of the season. Figure 4 shows the relationship between the uncertainty in demand and the value of reordering when the markdown is $100 \%$. The value of reordering reaches $\$ 0.4 \mathrm{M}$ at the maximum uncertainty analyzed. This is roughly a $20 \%$ increase in expected profits over the case where re-ordering is not allowed. 


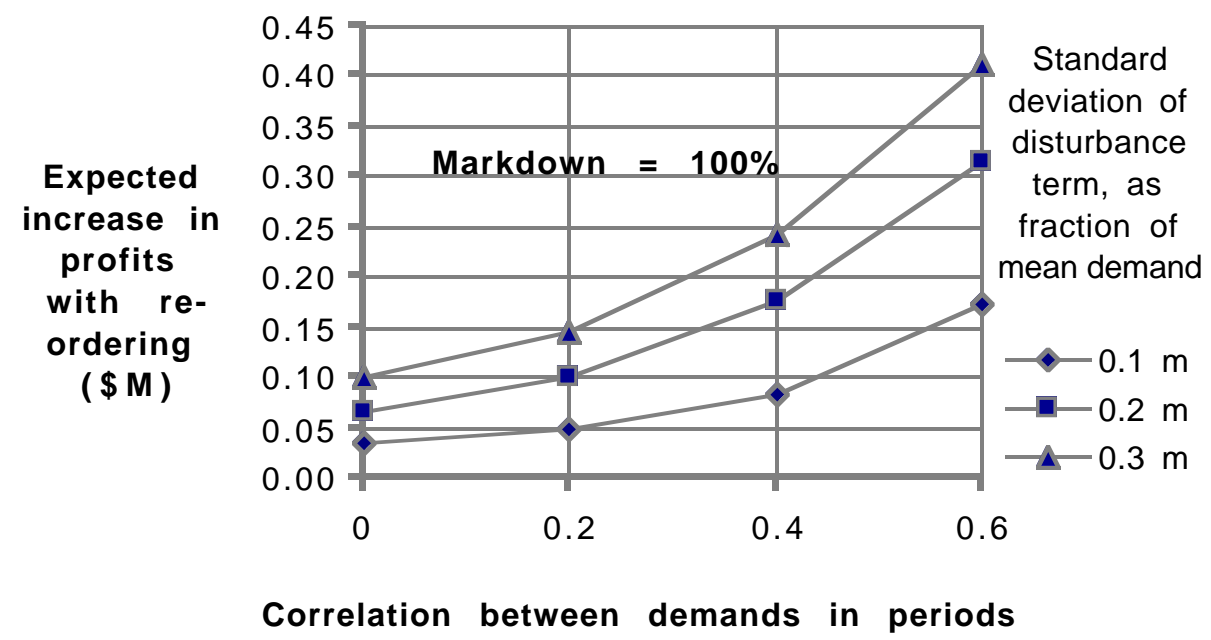

Figure 4: As the uncertainty in demands increases, the value of reordering increases

\section{Value of reordering depends on markdown at the end of the season}

When the markdown is large, there is substantial downside risk. However, as the markdown is reduced, the downside risk is reduced and expected profits tend to increase. Figure 5 shows the expected profits for the fixed order case when the markdown is only $50 \%$. Here the profits decline only slightly with the increase in uncertainty. Consequently, the difference between the expected profits with and without reordering is small so the value of reordering is small. 


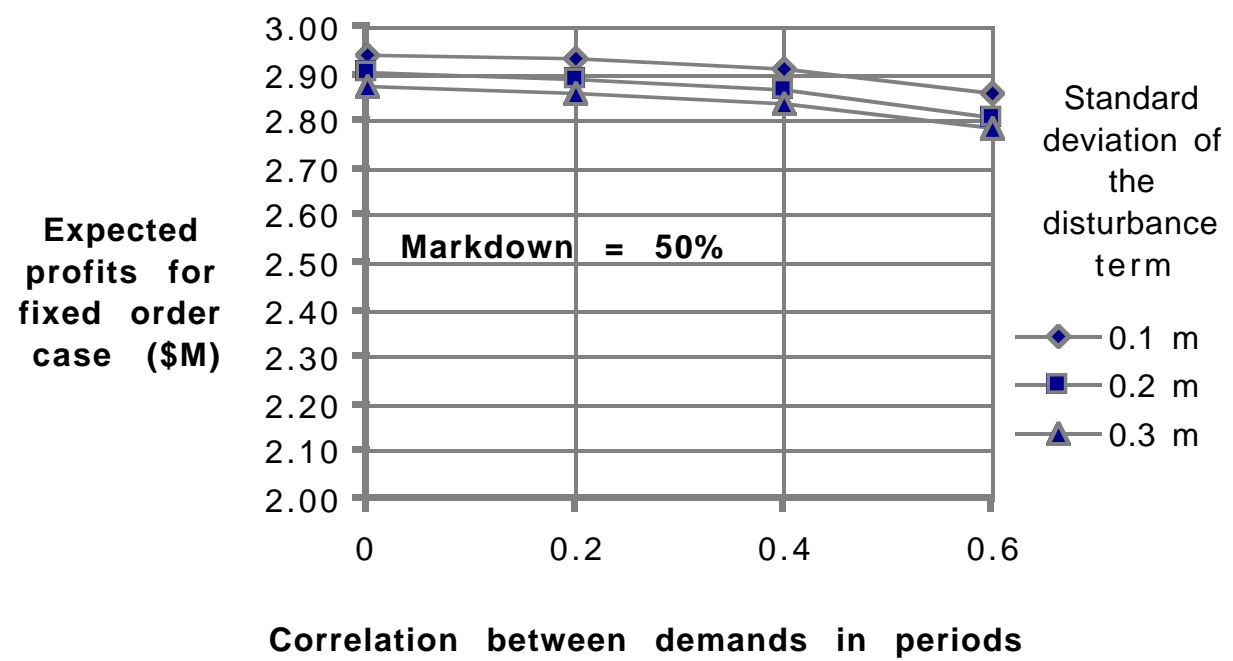

Figure 5: When the markdown is small, the expected profits do not decline rapidly as uncertainty increases for the fixed order case.

Figure 6 shows the results for the reorder case. Here the expected profit declines very slightly as uncertainty increases. In fact the decline is so small, that the discretization of the analysis results in curves that are not smooth.

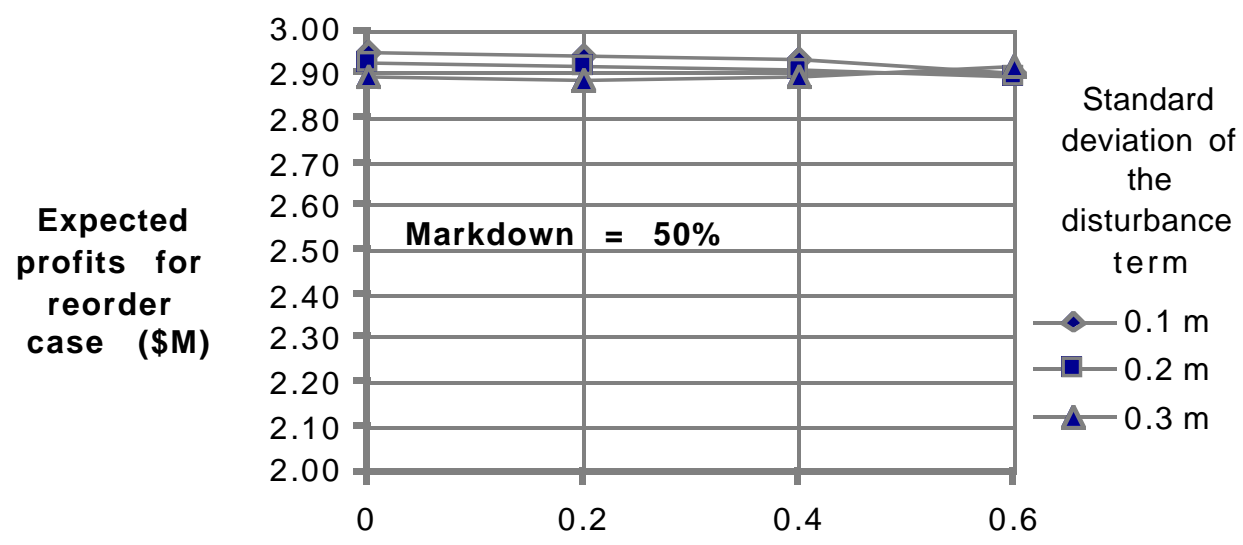

Correlation between demands in periods

Figure 6: When the markdown is small, the expected profits decline more slowly as uncertainty increases for the reorder case.(the curves plotted here-particularly the 0.3 case -do not decline smoothly due to the discretization in the analysis)

Figure 7 compares the expected value of reordering at $50 \%$ and $100 \%$ markdown. At a $50 \%$ markdown, the value of reordering is roughly a quarter of the value at a $100 \%$ markdown. This is shown 
for the case where the standard deviation of the disturbance term is 0.3 of the mean demand. The same general conclusion holds for the other cases.

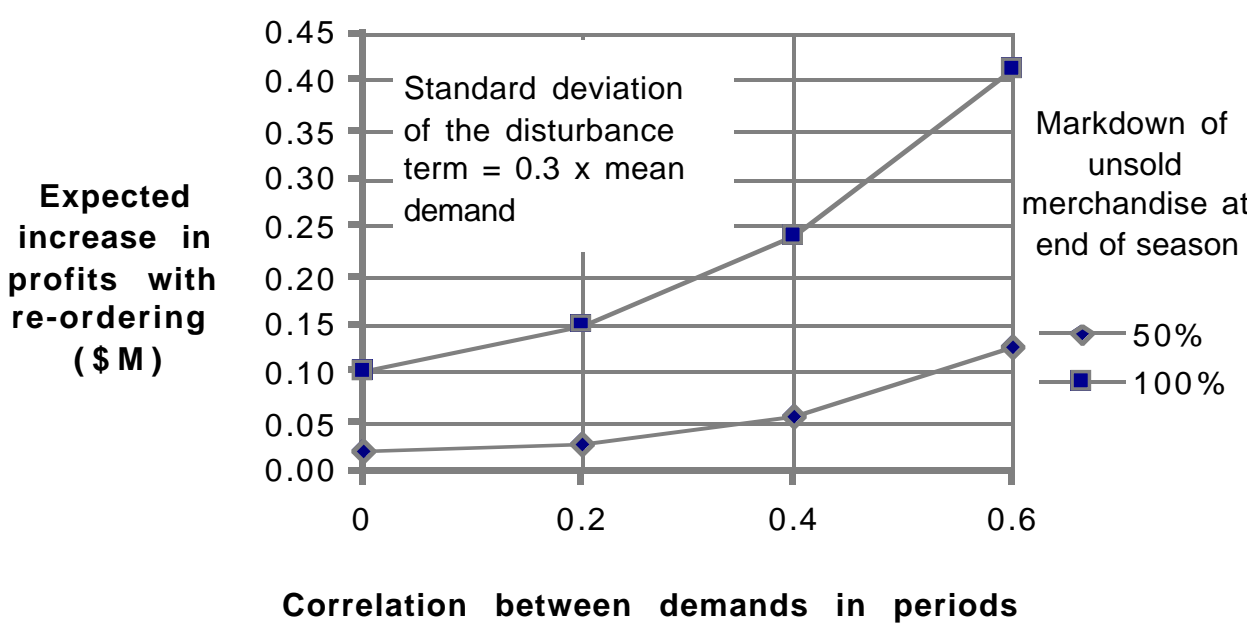

Figure 7: When the markdown is small, the expected value of reordering is markedly reduced

\section{Quantities ordered depend on demand statistics and markdown}

In each of the cases analyzed, we have determined the optimal quantities that the retailer should order, given the statistics of the demand and the markdown assumptions. As uncertainty increases there are some general trends in the optimal quantities. However, the directions of these trends depend on the markdown assumptions and whether or not reordering is allowed.

When the orders are fixed and the markdown is large, the optimal total quantity to order declines somewhat as the uncertainty increases. This is due to the downside risk. If there is excess stock at the end of the season, each unsold item represents a loss of more than $\$ 6$. Figure 8 shows that the optimal total order quantity declines from $50 \mathrm{k}$ doz to about $48 \mathrm{k}$ doz at the maximum uncertainty analyzed. 


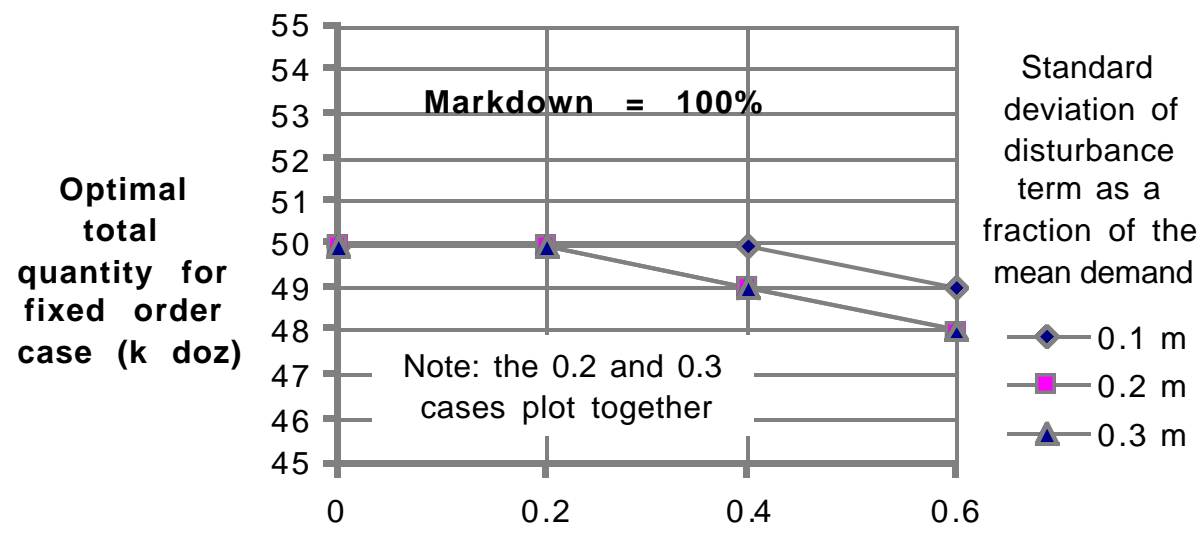

Correlation between demands in periods

Figure 8: When the markdown is large, the optimal total quantities to order decrease as uncertainty increase for the fixed order case

However, if the markdown is only $50 \%$, the optimal total quantity to order increases sharply for the fixed order case. Figure 9 shows that the optimal order quantity increases to about $72 \mathrm{k}$ doz at the maximum uncertainty analyzed. At a 50\% markdown any excess inventory represents a very small loss to the retailer (less than $\$ 0.50 \mathrm{pr}$ item) so the possibility of a smaller than expected demand represents very small losses. Conversely, if the demand turns out to be larger than expected, and there is enough stock on hand to meet the demand, then there is a large profit to be made on each extra item sold (more than $\$ 5$ ). Thus the retailer has a substantial incentive to order large amounts at a 50\% markdown. Moreover, the greater the uncertainty, the greater the chance of very high demands. Consequently the optimal order quantity increases as the uncertainty increases for a $50 \%$ markdown. 


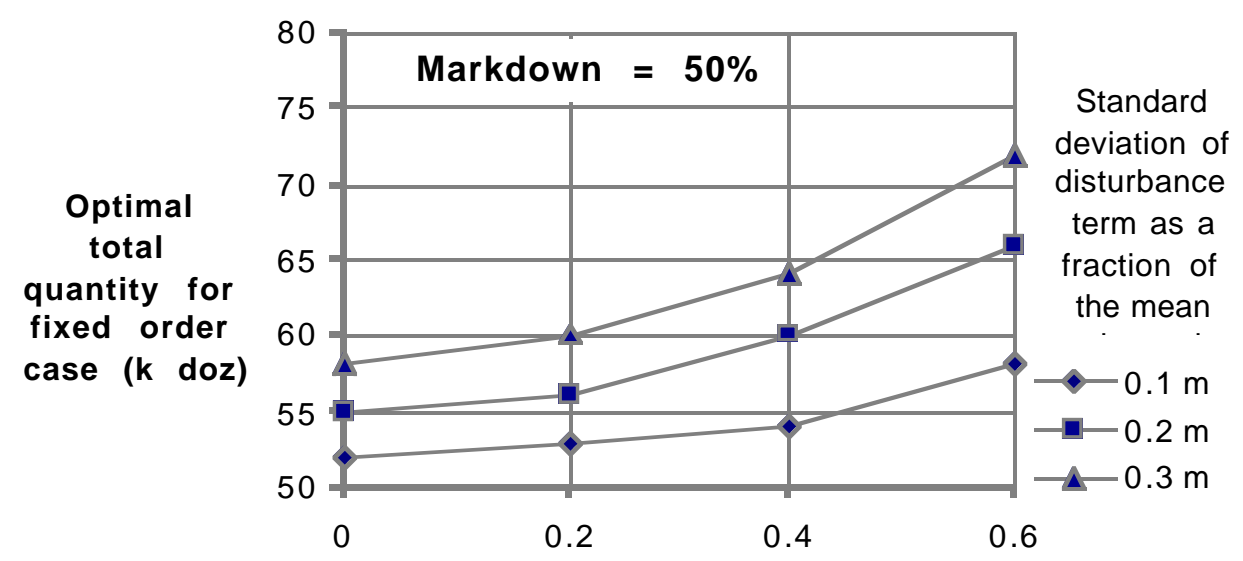

Correlation between demands in periods

Figure 9: When the markdown is small, the optimal total quantity to order increases for the fixed order case

In the case of reordering we can only examine the first order quantity since the second order quantity is probabilistic. Figure 10 and Figure 11 show a trend that is quite different from the fixed order case. For both large and small markdowns the optimal first quantity tends to increase slightly as uncertainty increases. This is due to the fact that as uncertainty increases, the chance of large demands in the first half of the season increases. If the retailer has enough stock on hand to serve this demand, he will obtain the profits from it. On the other hand, if demand turns out to be small during the first half season, he can always adjust his second order so as to reduce the chance of excess stock at the end of the season. 


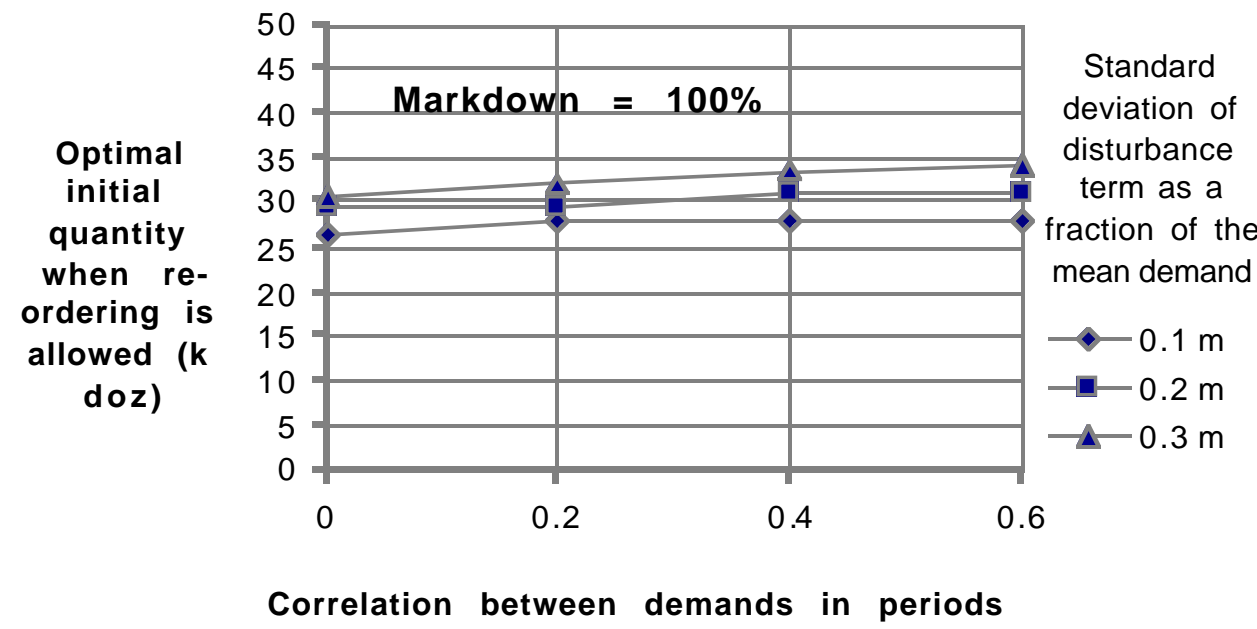

Figure 10: With large markdown for the reorder case the optimal quantity for the first order increases slightly as uncertainty increases. Note that the slight irregularities in the curves are due to the discretization in the calculations.

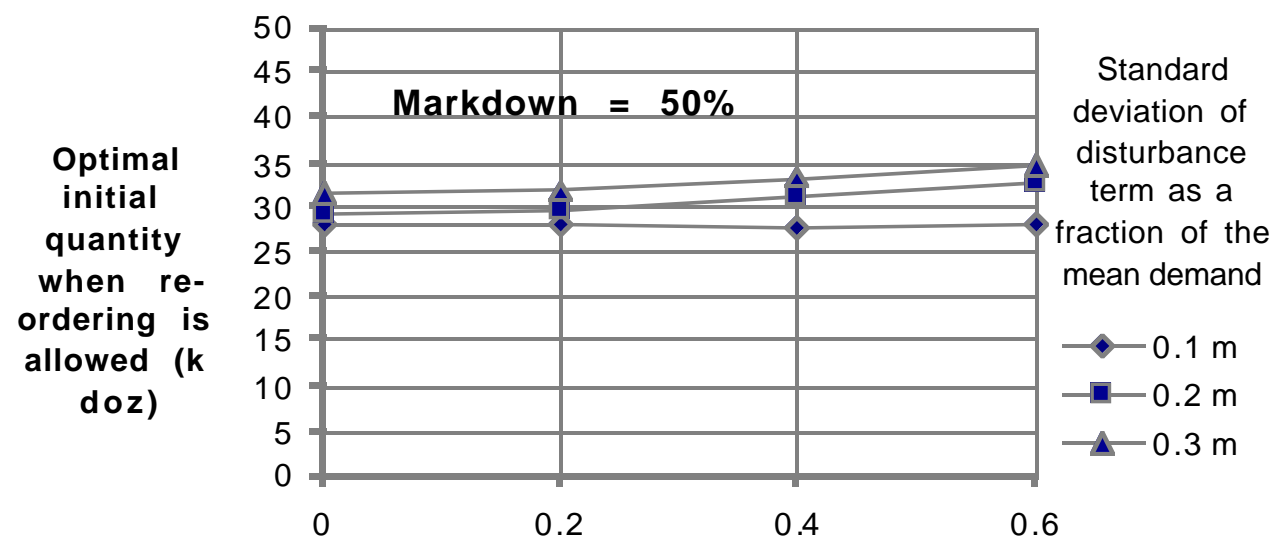

Correlation between demands in periods

Figure 11: When the markdown is 50\% for the reorder case the optimal quantity for the first order also rises slightly as uncertainty increases. Note that the slight irregularities in the curves are due to the discretization in the calculations.

From these results we see that the trend of quantities to purchase for the fixed order case is very sensitive to markdown: the direction reverses as the markdown increases. But, for the reorder 
case, the trend of the optimal first purchase is relatively insensitive to the markdown assumptions.

\section{Impact of reordering on price a retailer is willing to pay}

The analysis so far has shown that a retailer can expect higher profits when purchasing from a supplier that allows midseason reordering. If that is the case, then a retailer should be willing to pay a somewhat higher price to a supplier that allows reordering. As the price rises, the expected profits fall. A retailer would be willing to pay a premium price to a supplier that allows reordering, up to a price the causes expected profits to decline to the level of profit that he would expect from a supplier that does not allow reordering. This section evaluates the premium that a retailer should be willing to pay for the ability to reorder. The additional price that the retailer should be willing to pay can be estimated by dividing the increase in profits shown in Table 2 by the expected number of items (i.e. 50k doz). Technically, this calculation is not exact since, at a higher price, the retailer would change his order quantities slightly. To exactly compute the additional price that the retailer would be willing to pay, one should recompute the calculation of expected profits using several different values for price until the expected profits at the higher price are equal to the expected profits at the price charged by the supplier that does not allow reordering (in this example, \$6.00). This calculation was made for several different sets of parameter values. It showed that the approximate solution is accurate to within a few cents per item. The approximate calculation was used for the rest of the analysis.

Table 3 shows the additional price for each of the cases analyzed. The maximum increase that a retailer would pay is about $\$ 0.41$ in the case of a $100 \%$ markdown and maximum uncertainty about the demand. 
Table 3: The additional price that a retailer should be willing to pay in order to purchase from a supplier that allows reordering depends on the statistics of the demand and the markdown assumptions

\begin{tabular}{|c|c|c|}
\hline $\begin{array}{c}\text { Standard } \\
\text { Deviation of } \\
\text { Disturbance Term } \\
\text { (fraction of mean } \\
\text { demand) }\end{array}$ & $\begin{array}{l}\text { Correlation } \\
\text { Between } \\
\text { Period } \\
\text { Demands }\end{array}$ & $\begin{array}{l}\text { Additional } \\
\text { Price Retailer } \\
\text { would Pay for } \\
\text { Reordering } \\
\text { (\$/item) }\end{array}$ \\
\hline \multicolumn{3}{|l|}{ Markdown $\quad 100 \%$} \\
\hline 0.1 & 0.0 & 0.03 \\
\hline 0.1 & 0.2 & 0.05 \\
\hline 0.1 & 0.4 & 0.08 \\
\hline 0.1 & 0.6 & 0.17 \\
\hline 0.2 & 0.0 & 0.07 \\
\hline 0.2 & 0.2 & 0.10 \\
\hline 0.2 & 0.4 & 0.18 \\
\hline 0.2 & 0.6 & 0.31 \\
\hline 0.3 & 0.0 & 0.10 \\
\hline 0.3 & 0.2 & 0.14 \\
\hline 0.3 & 0.4 & 0.24 \\
\hline 0.3 & 0.6 & 0.41 \\
\hline \multicolumn{3}{|l|}{ Markdown $\quad 50 \%$} \\
\hline 0.1 & 0.0 & 0.00 \\
\hline 0.1 & 0.2 & 0.01 \\
\hline 0.1 & 0.4 & 0.02 \\
\hline 0.1 & 0.6 & 0.04 \\
\hline 0.2 & 0.0 & 0.02 \\
\hline 0.2 & 0.2 & 0.02 \\
\hline 0.2 & 0.4 & 0.04 \\
\hline 0.2 & 0.6 & 0.08 \\
\hline 0.3 & 0.0 & 0.02 \\
\hline 0.3 & 0.2 & 0.03 \\
\hline 0.3 & 0.4 & 0.06 \\
\hline 0.3 & 0.6 & 0.12 \\
\hline
\end{tabular}

\section{Conclusions and indications for further investigation}

The original motivation for this work was the comparison of on-shore and off-shore suppliers. Commonly, on-shore suppliers do charge a higher first cost, but also permit reordering. To make a decision between them, a retailer needs some way of assessing the additional value that the ability to reorder will produce. 
These results indicate that there is a clear relationship between the value of midseason reordering and well-defined parameters of a retailer's operating environment. This study shows that it is practical to assess the value of reordering when choosing suppliers.

The analysis presented here is restricted to a single reorder at midseason. It also assumes zero lead time for the order. Extensions to the model could evaluate multiple reorders during the season. It would be particularly valuable to determine whether or not the value of reordering tends to increase sharply as more reorders are allowed. It would also be important to determine the importance of the assumption about immediate delivery. If lead times are longer, one would expect that the value would decline since forecasts would be less accurate. However, without further analysis it is not clear whether the decline would be large or small. This question can be addressed through an extension of the model presented here. Ultimately, a tool could be developed to assist buyers in estimating the value of reordering for their particular demand and the cost structure of particular situation.

Throughout this analysis we have focused on the expected value of profits. For long-term decision making in a company, expected profits is often a good decision criterion. However, the variance of the distribution over profits (i.e. the range of possible profits) could also be significant for the retailer. If one alternative has a somewhat smaller expected profit but a small probability of a large loss, it may be preferred to another alternative that has a larger expected value but a larger probability of a large loss. One would expect that midseason reordering could change the variance of the distribution on profits as well as the expected value. Further analysis would be instructive. This could be done by restructuring some of the parts of this analysis so as to retain the information about the variance of the profits, or it could be done using a discrete event simulation model.

It was also assumed in this analysis that the retailer knows the parameters of the demand process and that he makes statistically optimal decisions. It is important to examine the impact of both of these assumptions. If a retailer does not know the underlying parameters of the demand, he must estimate them through observations (and perhaps other modelling). As is pointed 
out earlier, reordering has value even when estimates must be made as the season progresses since it make it possible to respond to new estimates. The analysis of this process and its value would require a different sort of model from that presented here. A simulation model such as that used by Nuttle, et al would be appropriate.

If the retailer does not make statistically optimal decisions, one would expect that the value of reordering would be smaller than what is shown here. However, it is quite possible that under a range of conditions simple heuristics decision rules may perform quite well. This question could also be addressed using a simulation model in which the decisions at each reorder point are based on a simpler heuristic. The average profits under the simpler methods could be compared to the expected values computed here.

\section{References}

Box, G. E. P, and G. M. Jenkins, Time Series Analysis, Forecasting And Control, Holden-Day, San Francisco, 1970

Harvey, A. C., Forecasting, Structural Time Series Models And Kalman Filter, Cambridge University Press, Cambridge, 1989

Nuttle, H.L.W, R.E. King and N.A. Hunter, "A Stochastic Model Of The Apparel-Retailing Process For Seasonal Apparel", Journal of the Textile Institute, 82 N0. 2, 1991 


\section{Appendix A Stochastic Demand Model}

This Appendix develops the equations of the demand model. This model is used to compute the probability distribution over the demands to compute the expected profits. It is also used to forecast demands to determine the quantities to order.

\section{Time series models}

The demand in a given time period is often correlated with demand in the previous time periods. Serial correlation (autocorrelation) is used to describe this situation. It exists when successive observations over time are related to each other. This correlation can be accounted for using autoregressive models described here.

Sets of observations taken in successive periods are usually referred to as "time series". The "autoregressive" (AR) model is one model used to describe patterns of time series data (see Box and Jenkins, or Harvey).

In an autoregressive model we denote the values of the series at equally spaced times $\mathrm{t}, \mathrm{t}-1, \mathrm{t}-2, \ldots$ by $x_{t}$. Here $\mathrm{x}_{\mathrm{t}}$ represents the demand at time $\mathrm{t}, x_{t-1}$, the demand at time $\mathrm{t}-1$, etc. Also define $\tilde{\mathrm{x}}_{\mathrm{t}}, \tilde{\mathrm{x}}_{\mathrm{t}-1}, \tilde{\mathrm{x}}_{\mathrm{t}-2}, \ldots$ to be the deviation from the mean demand, $\mu$; for example, $\tilde{x}_{t}=x_{t}-\mu$. Then

$$
\tilde{\mathrm{x}}_{\mathrm{t}}=\phi_{1} \bullet \tilde{\mathrm{x}}_{\mathrm{t}-1}+\phi_{2} \bullet \tilde{\mathrm{x}}_{\mathrm{t}-2}+\ldots+\phi_{\mathrm{p}} \bullet \tilde{\mathrm{x}}_{\mathrm{t}-\mathrm{p}}+\mathrm{e}_{\mathrm{t}}
$$

is called an autoregressive $(A R(p))$ process of order $p$. In this equation the variable $x$ is regressed on previous values of itself. The variable $e_{t}$ is the random error, where et is normally distributed with a mean of 0 and a standard deviation of $\sigma$ [i.e. $\left.e_{t} \sim N(0, \sigma)\right]$. In the autoregressive model the deviation $\tilde{x}_{t}$ is expressed as a weighted sum of $\mathrm{p}$ previous deviations and a random error $e_{t}$. 
This model has $p+2$ unknown parameters $\mu, \phi_{1}, \phi_{2}, \ldots, \phi_{\mathrm{p}}, \sigma$, which needs to be estimated. There are a number of procedures used to estimate the parameters of an autoregressive model from observed data (see Box and Jenkins).

\section{Demand forecast model}

For the on-shore supplier analysis, we use an autoregressive $A R(1)$ model to represent future demands. In the absence of demand data and for the purpose of illustrating the methodology, this stochastic model seems to adequately represent demand patterns. When sales data becomes available, more complex stochastic models could be explored.

We define the sales at period t to be $x_{t}$, and the deviation from the expected sales, $\mu$, to be $\tilde{x}_{t}=x_{t}-\mu$. Using an autoregressive $\mathrm{AR}(1)$ model, the deviations at time $\mathrm{t}$ can be written as

$$
\tilde{x}_{t}=\phi \tilde{x}_{t-1}+e_{t}
$$

where $\phi$ is the correlation between $\tilde{x}_{t}$ and $\tilde{x}_{t-1}$, and $e_{t}$ is a random term with mean zero and variance $\sigma_{e} 2 . \phi$ is assumed constant from period to period.

In this analysis we need to use the model of demands to forecast the distribution over future demands, given observations of past demands. Let us assume that we observe the demand up through period $\mathrm{s}$, then we estimate the total demand for the future periods. The mean and variance of the demand $\tau$ steps ahead are (see Box and Jenkins, or Harvey).

$$
\hat{\mathrm{x}}(\tau)=\tilde{\mathrm{x}}_{\mathrm{S}} \bullet \phi^{\tau}+\mu
$$

and

$$
\operatorname{var}(\tau)=\left\{1+\sum_{\mathrm{j}=1}^{\tau-1} \phi^{2 \mathrm{j}}\right\} \sigma_{\mathrm{e}}^{2}
$$

Assuming that the $e^{\prime} s$ are normal, then given information up to time $\mathrm{s}$, the conditional probability distribution $\mathrm{p}\left(\mathrm{x}_{\mathrm{s}+1} \mid \mathrm{x}_{\mathrm{s}}\right)$ of a future value 
of the process will be normal with mean and variance as specified above.

\section{Mean and variance of total demand over several periods}

At several points in the analysis it is necessary to compute the probability distribution over the sum of the demands for several periods, given the past observations of demands. The equations for the expected value and variance of the sums of demands, given the demand in period $\mathrm{s}$ are shown below (see Box and Jenkins, or Harvey). The expected total demand over $\mathrm{N}$ periods is

$$
\begin{aligned}
& \mu_{\mathrm{T}=} \sum_{\tau=1}^{\mathrm{N}} \hat{\mathrm{x}}(\tau) \\
& =\left\{\sum_{\mathrm{j}=1}^{\mathrm{N}} \phi^{\mathrm{j}}\right\} \mathrm{x}_{\mathrm{S}}+\mathrm{N} \cdot \mu
\end{aligned}
$$

where

$$
\begin{aligned}
& \mu \quad=\text { the expected demand during a period, } \\
& \hat{\mathrm{x}}(\tau)=\text { the expected demand in period } t \text {, from equation (A- } \\
& \quad 1), \\
& x_{s}=\text { the observed deviation in period } \mathrm{s} .
\end{aligned}
$$

The variance of total demand is

$$
\begin{aligned}
& \mathrm{v}_{\mathrm{t}}=\sum_{\tau=1}^{1} \mathrm{v}(\tau) \\
& =\left\{1+\sum_{\mathrm{k}=2}^{1} \sum_{\mathrm{j}=1}^{\mathrm{k}-1}\left(\phi^{2 \mathrm{j}}\right)\right\} \sigma_{\mathrm{e}}^{2}+2 \sum_{\mathrm{i}=1}^{1-1} \sum_{\mathrm{k}=\mathrm{i}+1}^{1} \phi^{\mathrm{k}-\mathrm{i}} \sigma_{\mathrm{i}} \sigma_{\mathrm{k}}
\end{aligned}
$$

where $\sigma_{i}$ and $\sigma_{k}$ are the standard deviations of the disturbance terms in periods $\mathrm{i}$ and $\mathrm{k}$. Here the standard deviations are all assumed to be equal to $\sigma_{\mathrm{e}}$. 


\section{Joint distribution of $\mathrm{D} 1$ and $\mathrm{D} 2$}

In these analyses the joint distribution over the demands in the first and second halves of the season is required. The forecast for the second half is based on the observed demand in the first half. If the demand in the second half is $\mathrm{D} 2$, then we need the probability distribution over D2, given D1. This is denoted $\mathrm{f}(\mathrm{D} 2 \mid \mathrm{D} 1)$. By expansion, the joint probability is calculated as:

$$
f(D 1, D 2)=f(D 2 \mid D 1) \cdot f(D 1)
$$

The structure of the demand model, however, implies that only the last period in the first half is relevant to estimating the demand in the second half since the demand in the fourth two-week period is only a function of the demand in the third two week period.

Let $\mathrm{d} 3$ be the demand in the in the last period of the first half of the season (this is the third two-week period of the season). The distribution over the demand in the first and second halves is computed as:

$$
f(D 1, D 2)=\int_{d 3} f(D 2 \mid d 3) \cdot f(d 3 \mid D 1)
$$

This requires that we derive an expression for the demand in the last period of the first half of the season, given the total amount for the first half of the season. This can be derived as:

$$
\mathrm{f}(\mathrm{d} 3 \mid \mathrm{D} 1)=\int_{\mathrm{e}_{1}} \mathrm{~N}\left(\mathrm{e}_{1}, \mu_{\mathrm{e}}, \sigma_{\mathrm{e}}\right) \cdot \mathrm{N}\left[\mathrm{D} 1-2 \cdot \mu_{\mathrm{d}}-\mathrm{e}_{1}-\mathrm{d}_{3}, \phi \bullet \mathrm{e}_{1}, \sigma_{\mathrm{e}}\right]
$$

where

$$
\begin{aligned}
\mathrm{N}(\mathrm{x}, \mu, \sigma)= & \text { the value of the normal distribution at } \mathrm{x} \text { with a mean } \\
& \text { of } \mu \text { and a standard deviation of } \sigma .
\end{aligned}
$$

The distribution over $f(D 2 \mid d 3)$ is directly computed from the equations above. D2 is normally distributed with a mean given by $(A-3)$, and variance given by $(A-4)$. This distribution is substituted into $(A-6)$ to obtain the joint distribution over D1 and D2. 


\section{Appendix B \\ Equations for Computing Optimal Order Quantities and Expected Net Present Value For Ordering Decisions}

\section{Introduction}

This model computes the statistically optimal ordering quantity and the net present value of revenues that a retailer would realize by ordering that quantity. The quantity ordered in the first period is the decision variable. We can then compute the maximum expected return under a range of parameters describing the uncertainty in demand and the markdown at the end of the season. This illustrates the relationship between expected return and the parameters. The sections below describe the structure of the model.

We define the equations for calculating the expected net present value of revenue (profits) given the quantities ordered and for determining the optimal quantities to order. The sections below first define the quantities to be used and the structure of the periods. We then present the equations for computing the expected value of profits given the order quantities for both halves of the season are fixed. Finally, we present the procedure for determining the optimal first quantity and the expected value for the reordering case.

\section{Some Basic Definitions}

This section defines the notations which are referred to a various points in the discussion below.

The structure of the periods and quantities is illustrated below. The season is divided into six periods of two weeks each. The demand during the ith period is di. The total demand over the 
first and second halves are D1 and D2. The amounts ordered for the first and second halves are Q1 and Q2.

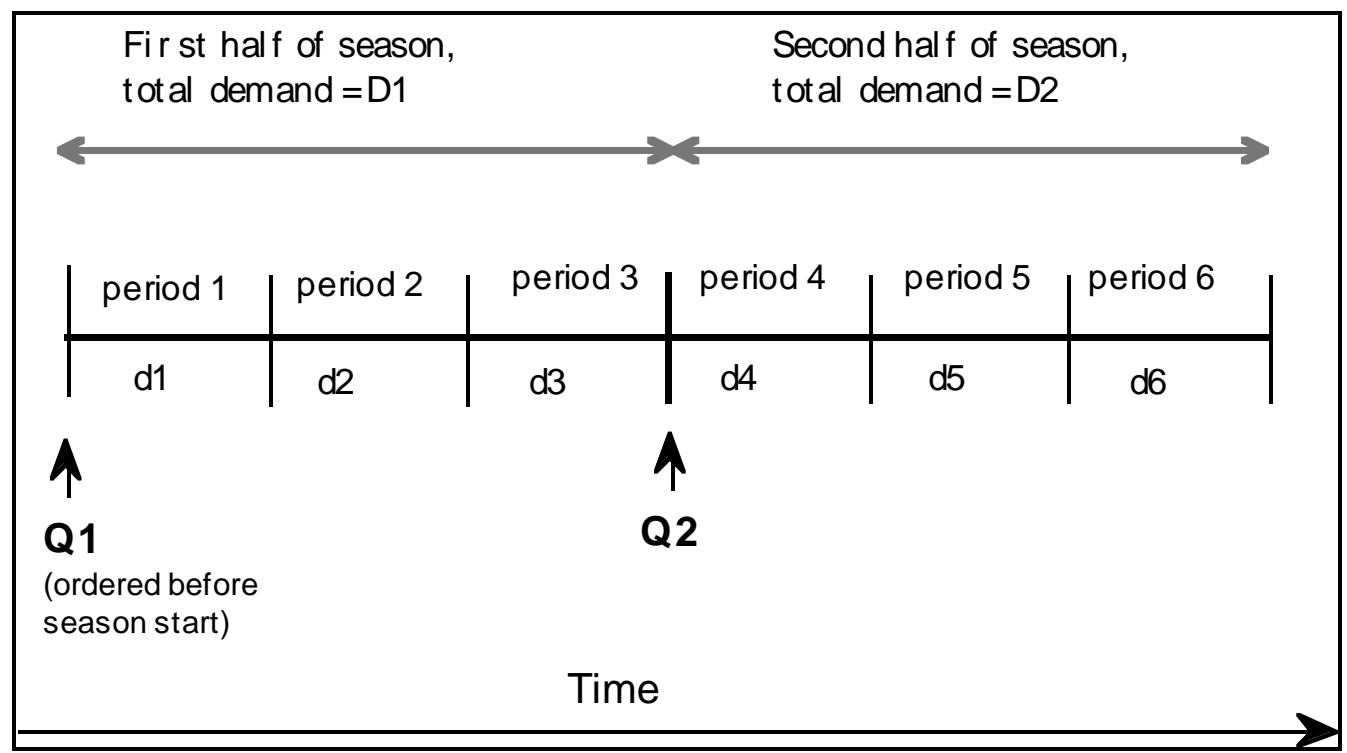

It is assumed that the sales during a period are spread out through the period.

Before starting it is useful to define a number of variables, quantities and functions that will simplify the discussion below:

$\mathrm{dn}_{\mathrm{n}}=$ the potential demand during the nth period. This is the number of units that would be sold if there were no stockouts.

$\mathrm{D}_{\mathrm{i}} \quad=$ the total demand during the ith half of the season

sohi $_{i}=$ the stock on hand at the start of the nth half of the season.

$\mathrm{Q}_{\mathrm{i}}=$ the quantity purchased in half season $\mathrm{i}$ (number of units).

$\mathrm{Pp}_{\mathrm{i}}=$ purchase price per item ordered for the ith half of the season.

Ps $\quad=$ sales price per item.

$\mathrm{si}=$ actual sales during half season $\mathrm{i}$ (number of units). 
$\alpha=a$ discount factor that discounts total revenue during a period back to the start of the period, assuming that the revenue is received in a uniform stream.

$\beta=$ a discount factor that discounts a lump sum received at the end of a period back to the start of the period.

It is also helpful to define several functions and other notations that will be used in the sections below.

The quantity actually sold in half season $i$ is a function of the potential demand, the stock on hand at the start of the period, and the amount ordered:

$$
\mathrm{s}_{\mathrm{i}}\left(\mathrm{D}_{\mathrm{i}}, \operatorname{soh}_{\mathrm{i}}, \mathrm{Q}_{\mathrm{i}}\right)=\min \left(\mathrm{D}_{\mathrm{i}}, \operatorname{soh}_{\mathrm{i}}+\mathrm{Q}_{\mathrm{i}}\right)
$$

Revenues in period $n$ are:

$$
\alpha \bullet \mathrm{s}_{\mathrm{n}}\left(\mathrm{D}_{\mathrm{n}}, \operatorname{soh}_{\mathrm{n}}, \mathrm{Q}_{\mathrm{n}}\right) \bullet \mathrm{P}_{\mathrm{s}}
$$

Purchase costs in period $\mathrm{i}$ are

$$
\mathrm{Q}_{\mathrm{i}} \bullet \mathrm{Pp}_{\mathrm{i}}
$$

\section{Case Where Orders Are Fixed Before Season Starts}

In this case we need to determine the expected present value of revenues as a function of the quantities ordered (Q1 and Q2) and the demands (D1 and D2). This is computed as:

$$
\begin{aligned}
& \text { PV_Rev }(\mathrm{Q} 1, \mathrm{D} 1, \mathrm{Q} 2, \mathrm{D} 2)=\alpha \cdot \mathrm{s}_{1}\left(\mathrm{D} 1, \operatorname{soh}_{1}, \mathrm{Q} 1\right) \cdot \mathrm{Ps}+\alpha \cdot \beta \cdot \mathrm{s}_{2}\left(\mathrm{D} 2, \mathrm{soh}_{2}, \mathrm{Q} 2\right)(\mathrm{B}-1) \\
& \text { Where } \\
& \text { soh }_{1}=0 \\
& \text { soh }_{2}=\max (\mathrm{Q} 1-\mathrm{D} 1,0)
\end{aligned}
$$

The body of the report shows the remaining equations needed to compute the expected present value of revenues. 


\section{The midseason reorder case}

Here we consider a case were there are two halves to the season. The quantity for the first half of the season is fixed and the second quantity is decided at midseason. We wish to determine the amount to order in the first half which will maximize the expected net present value over the entire season.

The strategy for computing the total expected benefits is based on dynamic programming. Under this approach a recursive equation is defined. For each period up to the last period we can write an equation for the expected net revenues that is a sum of net revenues from that period, plus the expected net revenues from the future periods. The future period revenues are written as a function of the decision made in the current period (the quantity purchased), all of the previous decisions and outcomes, and the demand in the current period. For the last period, there is no future net revenue, so the net revenues are solely a function of what occurs in that period. This allows us to terminate the recursion and actually compute an answer.

The total discounted value as a function of the demand during the first half, and the amount ordered after the first half is

$$
\mathrm{V}_{1}(\mathrm{D} 1, \mathrm{Q} 1)=\alpha \cdot \mathrm{s}_{1}(\mathrm{D} 1, \mathrm{Q} 1) \cdot \mathrm{P}_{\mathrm{s}}-\mathrm{Q} 1 \cdot \mathrm{P}_{\mathrm{p}}+\beta \bullet \overline{\mathrm{V}}_{2}^{*}(\mathrm{D} 1, \mathrm{Q} 1)
$$

Here the quantity $\bar{V}_{2}^{*}(D 1, Q 1)$ is the future expected net revenues, given the demand during first half, the first order quantity, and assuming that the optimal decisions are made in the last period.

The expected value at the start of the first period, as a function of the quantity ordered is

$$
\overline{\mathrm{V}}_{1}(\mathrm{Q} 1)=\int_{\mathrm{D} 1} \mathrm{~V}_{1}(\mathrm{D} 1, \mathrm{Q} 1) \bullet \mathrm{f}(\mathrm{D} 1)
$$

Where

$\mathrm{f}(\mathrm{D} 1)=$ the probability distribution over the demand in the first half of the season

By substituting (B-2) into (B-3) this can be expanded to: 


$$
\begin{aligned}
& \overline{\mathrm{V}}_{1}(\mathrm{Q} 1)= \\
& \int_{\mathrm{D} 1}\left[\alpha \cdot \mathrm{s}_{1}(\mathrm{D} 1, \mathrm{Q} 1) \cdot \mathrm{P}_{\mathrm{S}}-\mathrm{Q} 1 \cdot \mathrm{Pp}_{1}+\beta \bullet \overline{\mathrm{V}}_{2}^{*}(\mathrm{D} 1, \mathrm{Q} 1)\right] \bullet \mathrm{f}(\mathrm{D} 1)
\end{aligned}
$$

To evaluate this, we need to evaluate the term $\bar{V}_{2}^{*}(\mathrm{D} 1, \mathrm{Q} 1)$. This is fairly straightforward if we start from the basic definition of the value from decision during the second half:

$$
\mathrm{V}_{2}(\mathrm{D} 1, \mathrm{Q} 1, \mathrm{D} 2, \mathrm{Q} 2)=\alpha \cdot \mathrm{s}_{2}\left(\mathrm{D} 2, \mathrm{soh}_{2}, \mathrm{Q} 2\right) \cdot \mathrm{P}_{\mathrm{s}}-\mathrm{Q} 2 \cdot \mathrm{P}_{\mathrm{p}}
$$

but soh2 can be written as a function of the D1 and Q1:

$$
\operatorname{soh}_{2}(\mathrm{D} 1, \mathrm{Q} 1)=\max (\mathrm{Q} 1-\mathrm{D} 1,0)
$$

Thus, the value $\mathrm{V}_{2}$ can be written as a function D1,Q1,D2,Q2:

$$
\mathrm{V}_{2}(\mathrm{D} 1, \mathrm{Q} 1, \mathrm{D} 2, \mathrm{Q} 2)=\alpha \cdot \mathrm{s}_{2}\left[\mathrm{D} 2, \mathrm{soh}_{2}(\mathrm{D} 1, \mathrm{Q} 1), \mathrm{Q} 2\right] \cdot \mathrm{P}_{\mathrm{s}}-\mathrm{Q} 2 \cdot \mathrm{Pp}_{2}
$$

The expected value is:

$$
\begin{aligned}
& \overline{\mathrm{V}}_{2}(\mathrm{D} 1, \mathrm{Q} 1, \mathrm{Q} 2)= \\
& \int_{\mathrm{D} 2}\left[\alpha \cdot \mathrm{s}_{2}\left[\mathrm{soh}_{2}(\mathrm{D} 1, \mathrm{Q} 1), \mathrm{D} 2, \mathrm{Q} 2\right] \cdot \mathrm{P}_{\mathrm{s}}-\mathrm{Q} 2 \cdot \mathrm{Pp}_{2}\right] \bullet \mathrm{f}(\mathrm{D} 2 \mid \mathrm{D} 1)
\end{aligned}
$$

We can now find the maximum value by taking the max over Q2:

$$
\overline{\mathrm{V}}_{2}^{*}\left(\operatorname{soh}_{2}, \mathrm{D} 1, \mathrm{Q} 1\right)=\max _{\mathrm{Q} 2}\left[\overline{\mathrm{V}}_{2}\left(\operatorname{soh}_{2}, \mathrm{D} 1, \mathrm{Q} 1, \mathrm{Q} 2\right)\right]
$$

This completely defines the calculations needed to compute the expected value as a function of the quantity purchased in the first half of the season. Substituting equation (B-9) into equation (B-2) allows us to calculate $V_{1}(D 1, Q 1)$. The expected value from both halves of the season, as a function of the quantity purchased at the start of the season is just:

$$
\overline{V_{1}}(\mathrm{Q} 1)=\int_{D 1} \mathrm{~V}_{1}(\mathrm{D} 1, \mathrm{Q} 1) \bullet f(\mathrm{D} 1)
$$

We can then find the value of $\mathrm{Q} 1$ that gives the maximum value. The maximum expected value, given the stock on hand is

$$
\overline{\mathrm{V}}_{1}^{*}=\max _{\mathrm{Q} 1}\left[\overline{\mathrm{V}_{1}}(\mathrm{Q} 1)\right]
$$


This gives the expected value of the optimal policy. The value of $\mathrm{Q} 1$ that maximizes the expression is the optimal amount to order for the start of the season. 


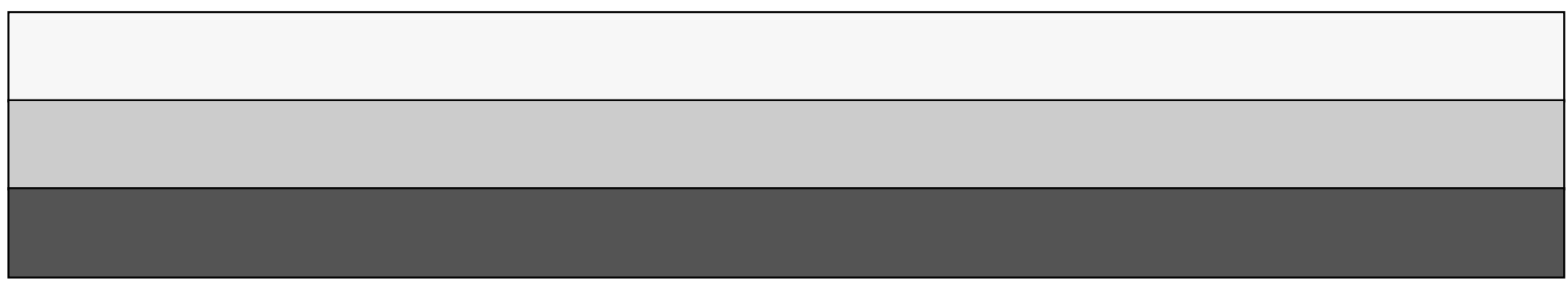

